\title{
Metal/Semiconductor and Transparent Conductor/Semiconductor Heterojunctions in High Efficient Photoelectric Devices: Progress and Features
}

\author{
M. Melvin David Kumar, ${ }^{1}$ Ju-Hyung Yun, ${ }^{1,2}$ and Joondong Kim ${ }^{1}$ \\ ${ }^{1}$ Department of Electrical Engineering, Incheon National University, Incheon 406772, Republic of Korea \\ ${ }^{2}$ Department of Electrical Engineering, University at Buffalo, State University of New York, Buffalo, NY 14260, USA \\ Correspondence should be addressed to Joondong Kim; joonkim@incheon.ac.kr
}

Received 26 May 2014; Revised 29 August 2014; Accepted 30 August 2014; Published 22 September 2014

Academic Editor: Yuexiang Li

Copyright (C) 2014 M. Melvin David Kumar et al. This is an open access article distributed under the Creative Commons Attribution License, which permits unrestricted use, distribution, and reproduction in any medium, provided the original work is properly cited.

Metal/semiconductor and transparent conductive oxide (TCO)/semiconductor heterojunctions have emerged as an effective modality in the fabrication of photoelectric devices. This review is following a recent shift toward the engineering of TCO layers and structured Si substrates, incorporating metal nanoparticles for the development of next-generation photoelectric devices. Beneficial progress which helps to increase the efficiency and reduce the cost, has been sequenced based on efficient technologies involved in making novel substrates, TCO layers, and electrodes. The electrical and optical properties of indium tin oxide (ITO) and aluminum doped zinc oxide (AZO) thin films can be enhanced by structuring the surface of TCO layers. The TCO layers embedded with Ag nanoparticles are used to enhance the plasmonic light trapping effect in order to increase the energy harvesting nature of photoelectric devices. Si nanopillar structures which are fabricated by photolithography-free technique are used to increase lightactive surface region. The importance of the structure and area of front electrodes and the effect of temperature at the junction are the value added discussions in this review.

\section{Introduction}

Harvesting solar energy in order to produce electricity is the possible and eco-friendly solution to the energy crisis in the world. The future challenge in front of the photoelectric researches and industries is to produce lower cost and higher efficiency devices [1]. However, the conventional Si photovoltaics with low defect wafer are very expensive and complicated processing techniques such as wet chemical treatment, high temperature furnace steps, and time-cost metallization. Recently, significant works have been put forward to produce low cost photoelectric devices by using thin film technology imbibing with heterojunction concept. The term heterojunction more often denotes the interface between any two solid-state materials having different structural and optical properties. In most of the heterojunction solar cells, the device junction is formed between TCO and $\mathrm{Si}$ or metal and Si. The TCOs are binary or ternary compounds, containing one or two metallic elements. Their resistivity could be in the order of $10^{-5} \Omega \mathrm{cm}$, and their extinction coefficient in the visible range could be lower than 0.0001, because of their wide optical band gap $\left(E_{g}\right)$ which is greater than $3 \mathrm{eV}$. Heterojunctions of TCO/Si and Metal/Si are the promising and viable method to develop low cost devices. And, the photoelectric devices consisting of semiconductorinsulator TCO are also preferred because they do not require obtaining $\mathrm{p}-\mathrm{n}$ junction. Here, the separation of the charge carriers can be realized at the interface. By depositing TCO thin films on the oxidized semiconductors like $\mathrm{SiO}_{x}$, these structures can be obtained [2]. The most utilized TCO layers are indium tin oxide (ITO) and aluminum doped zinc oxide (AZO). When compared to conventional solar cells, the photoresponse in TCO/Si heterojunction devices is higher because of their large band gaps. In particular, the energy 
band gaps of ITO and AZO materials are 3.8 and $3.37 \mathrm{eV}$, respectively, so that these films are totally transparent in the region of solar spectrum, thereby increasing photoresponse still more. The efficiency of these kinds of devices can reach the value of more than 10\% [3]. Furthermore, the transparent conducting layers of ITO and AZO can act as ohmic contacts, rectifying junctions, antireflectors, and passivation layer proficiently. Hence, preparation of photoelectric devices using these materials is the promising approach to reduce the cost and increase the efficiency [4]. As a next step of this continuation, sincere efforts have been taken by few researchers to improve the efficiency of $\mathrm{TCO} / \mathrm{Si}$ heterojunction devices by means of familiarizing many new ideas such as patterning of ITO, combining of two different TCOs, rapid thermal treatment, introducing nanoparticles, creating textured Si substrates, and changing number of electrode fingers in front electrodes, in the photoelectric devices. As an example, the AZO thin film has been successfully used with Si nanopillars (SiNP) to enhance the light harvesting efficiency of photoelectric devices. This device $(\mathrm{AZO} / \mathrm{n}-\mathrm{AZO} / \mathrm{p}-\mathrm{SiNP} / \mathrm{p}-\mathrm{Si})$ has been fabricated by the state of the art processing which is explained in this paper in detail. The structural, optical, and electrical properties of the TCO/semiconductor and metal/semiconductor heterojunction devices were characterized by XRD, SEM, HRTEM, UV-VIS spectrophotometer, and $I-V$ characteristic measurements, respectively. The main objective of the paper is to review the progress through $\mathrm{TCO} /$ semiconductor and metal/semiconductor heterojunctions along with their reported results to explore novel methods to improve the performance of devices. In addition to that, advantages, applications, and features of heterojunction devices are also discussed.

\section{Advanced Progress in Heterojunction Devices}

Photoelectric devices such as solar cells and photodetectors with heterojunction contacts are able to achieve high electrical voltages. In particular, the semiconductors with TCOs and metals are the prominent ones in achieving high efficient photoelectric devices. Even a slight modification in the structure of substrate or TCO layer or front/back ohmic contacts can make notable differences in the output performance of a device. The innovative progress reported in recent researches in heterojunction devices is sectioned under suitable headings here in detail.

2.1. Patterned TCO Layers. The enhanced optical path length of incident light simultaneously increases the efficiency of devices. This can be achieved if the incident light scatters at the interface between a TCO layer and a Si light absorbing substrate with different refractive indices, so that light is trapped within the $\mathrm{Si}$ absorber layer. In addition to high transparency and high electrical conductivity, a TCO layer can act as front electrode which ensures efficient scattering of the incoming light into the absorber layer. Therefore, it is understood that TCO layer plays a vital role in device performance of solar cells and photodetectors. An attractive method of preparing three-dimensionally (3D) patterned and nanodome patterned TCO layers has been proposed $[5,6]$ to enhance the incident light management and response of photoelectric devices, respectively.

3D patterned TCO layer was formed by dual ITO depositions. A flat $\mathrm{Si}$ substrate was employed to provide clear images of the 3D TCO structures. In this process, initially photoresist (PR) mask was prepared by spin coating method at $3000 \mathrm{rpm}$ for $30 \mathrm{sec}$ to have $2 \mu \mathrm{m}$ thickness. After exposing UV light at $200 \mathrm{~W}$, the PR patterns were developed. The initial ITO coating was performed on the PR masked substrate. The ITO dots were obtained by removing PR mask. Then, additional ITO layer was coated on ITO dots to connect them electrically. The step-by-step procedure of preparing 3D ITO dots is shown in Figure 1(a). The SEM images of 3D ITO dots and second ITO layer which connects all the ITO dots are shown in Figures 1(b) and 1(c), respectively.

Significant improvement was observed in both internal and external quantum efficiencies (IQE and EQE) of 3D patterned TCO structure when comparing the results with planar TCO layer. Moreover, 3D ITO structure works as a lens to drive more photons into a Si light absorber and it efficiently drives the electric field into a $\mathrm{Si}$ absorber suggesting the effective photon delivery close to a space charge region. The 3D structure improved the IQE value of $89.95 \%$ from $83.36 \%$ of planar ITO layer. The enhanced efficiency of $14.3 \%$ was achieved from the 3D TCO-integrated device due to its high current density $\left(J_{\mathrm{sc}}\right)$ of $29.56 \mathrm{~mA} / \mathrm{cm}^{2}$ which is greater than that of planar ITO film $\left(25.92 \mathrm{~mA} / \mathrm{cm}^{2}\right)$. This result strongly indicates that architecture with a front surface of TCO layers can provide efficient light management for solar cells.

Similar to 3D ITO dots, nanodome patterned TCO layer on $\mathrm{p}$-Si substrate was prepared by nanoimprint method. A prepatterned polymer mold (polyurethane acrylate, PUA) was pressed on a PMMA (poly methyl meth acrylate) layer and removed to leave PMMA nanoscale patterns on the Si substrate. After this, sputtering was performed to coat an ITO layer along the PMMA pattern. A lift-off process was used to remove the ITO coating on the PMMA pattern and to remain the ITO nanodome structures on the Si substrate. The processing steps to prepare ITO nanodome and SEM images of top and front view of ITO nanodomes are shown in Figures 2(a), 2(b), and 2(c), respectively.

ITO nanodome device provides excellent IQE performance, especially for the incident light-active wavelengths $(500-1100 \mathrm{~nm})$ of $\mathrm{Si}$. This is a significant improvement incurred by using the nanodome ITO structure. The planar ITO heterojunction device showed extremely poor carrier collection efficiency over a wide range of wavelengths as shown in Figure 3(a). A planar ITO film shows an effective reduction in the reflection $(29.11 \%)$ of the incident light. However, an ITO nanodome structure substantially reduces the reflection, leaving it at a value of $12.55 \%$ as shown in Figure 3(b). This strongly indicates that the advantages of the ITO nanodome structures can be realized in practical applications. The refractive index effect of planar ITO is lower than that of texture ITO. It is interesting to note that the 


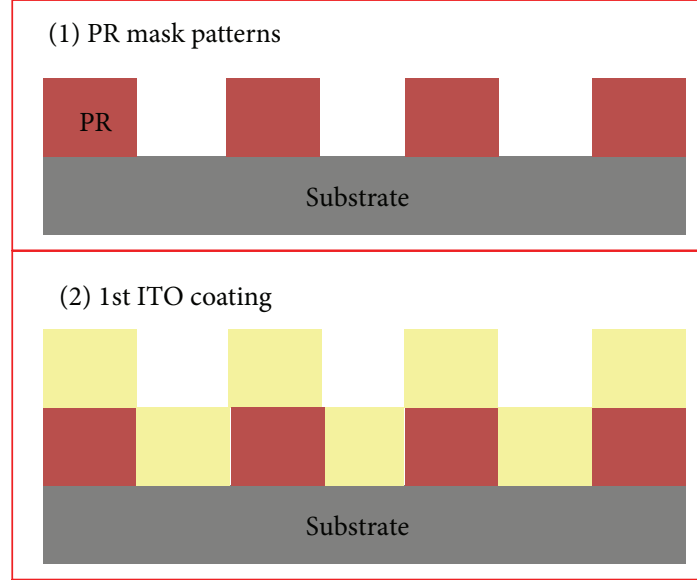

(3) PR stripping

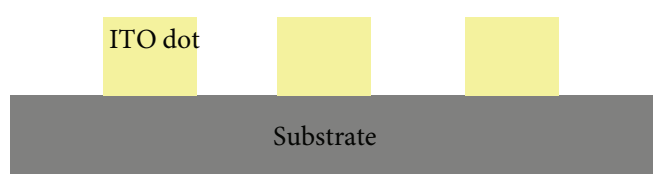

(4) 2nd ITO coating

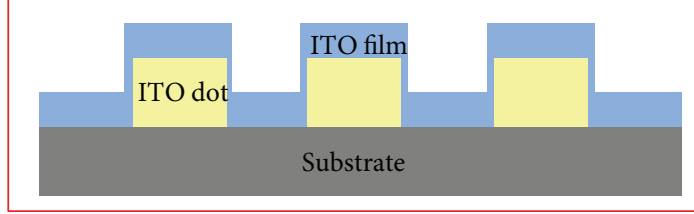

(a)

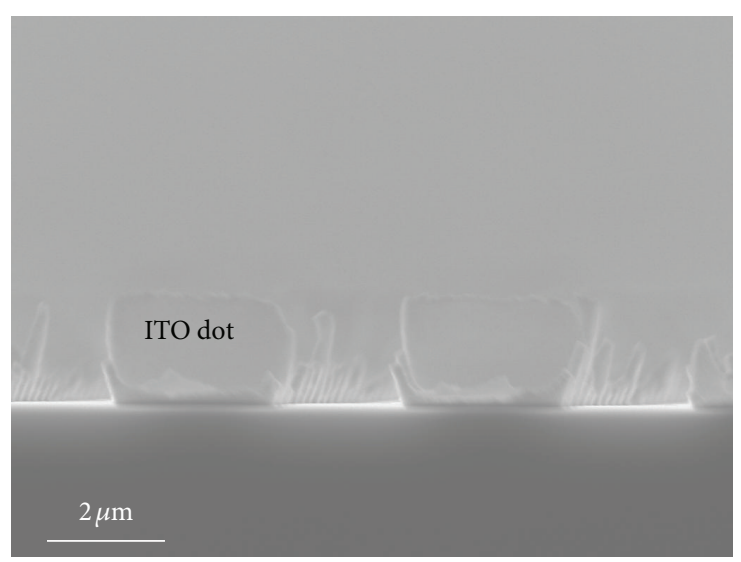

(b)

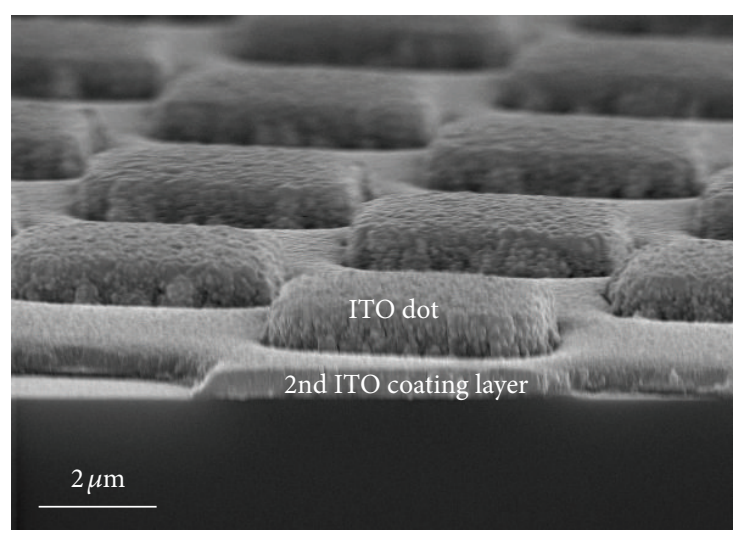

(c)

FIGURE 1: (a) Step-by-step procedure of preparing 3D ITO dots; (b) SEM image of 3D ITO dot after PR stripping; (c) SEM image of 3D ITO dot covered with second ITO layer that connects all dots [5].

nanostructures like nanodots and nanodomes could enhance light extraction/absorption in solar cells and LEDs, thus improving device performance. From both aforementioned reports, it is clearly predicted that the patterned TCO layers perform well in all aspects compared with ordinary planar TCO layers in photoelectric devices.

2.2. Double Layers of TCO. The total amount of indium reserves in the world is estimated to be approximately 6000 tons according to the year 2007 United States Geological Survey. It is widely believed that indium shortage may occur in the very near future and indium will soon become a strategic resource in every country [7]. From the recent researches, $\mathrm{ZnO}$ and doped- $\mathrm{ZnO}$ materials are the upcoming competent alternate to ITO. $\mathrm{ZnO}$ is typically an n-type semiconductor with electron affinity of $4.35 \mathrm{eV}$ and direct band gap energy of $3.30 \mathrm{eV}$. On the other hand, the doped- $\mathrm{ZnO}$ films have been realized with very attractive electrical and optical properties for photovoltaic applications. And, there has been much interest in AZO as a promising candidate for cost reduction. AZO has advantages of chemical selectivity, mechanical properties, and thermal stability [8]. Since ITO provides excellent electrical conductivity and AZO has good optical transparency, multilayer TCO (AZO/ITO) structures have advantages of more improved visible transmission and the electrical conductivity than single AZO and ITO films [9-11]. In the research work of Yun et al. [2, 12], the optical and electrical characteristics of bilayer TCO structures coated on $\mathrm{n}-\mathrm{Si}$ substrate were compared with single layers of ITO and AZO devices effectively and the results showed that the AZO/ITO films have performed well in the aspects of higher optical transparency and electrical conductivity compared to those values of single ITO and AZO layers.

The bilayer samples were coated on both glass substrates and $\mathrm{SiO}_{2}$-coated $\mathrm{Si}$ substrates for characterizing optical and electrical properties of the device, respectively. The lowmagnification TEM images showing columnar growth of bilayer (AZO/ITO) and single layer (AZO and ITO) films are shown in Figures 4(a), 4(b), and 4(c), respectively.

AZO layer has high optical transparency of $80.8 \%$ whereas it is only of $75.3 \%$ for single ITO layer. When these two TCOs are combined together in a device, the optical transparency is enhanced to $79 \%$ which is nevertheless close to that of single AZO layer. The optical profile of bilayer TCO samples along with single layers is shown in Figure 5. 

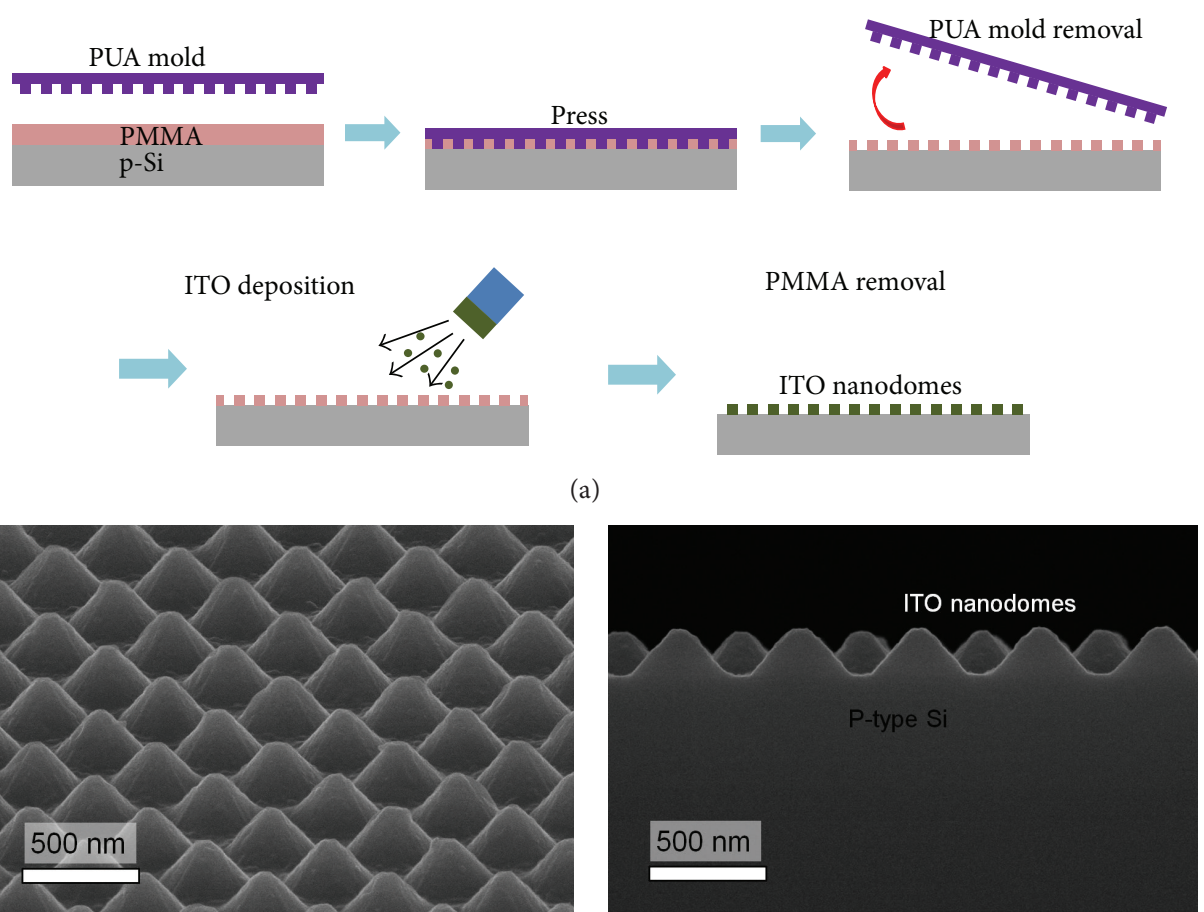

(b)

(c)

FIGURE 2: (a) Schematic illustrations of processing steps of preparing ITO nanodomes; (b) SEM image of nanodomes at top view; (c) SEM image of nanodomes at cross-sectional view [6].

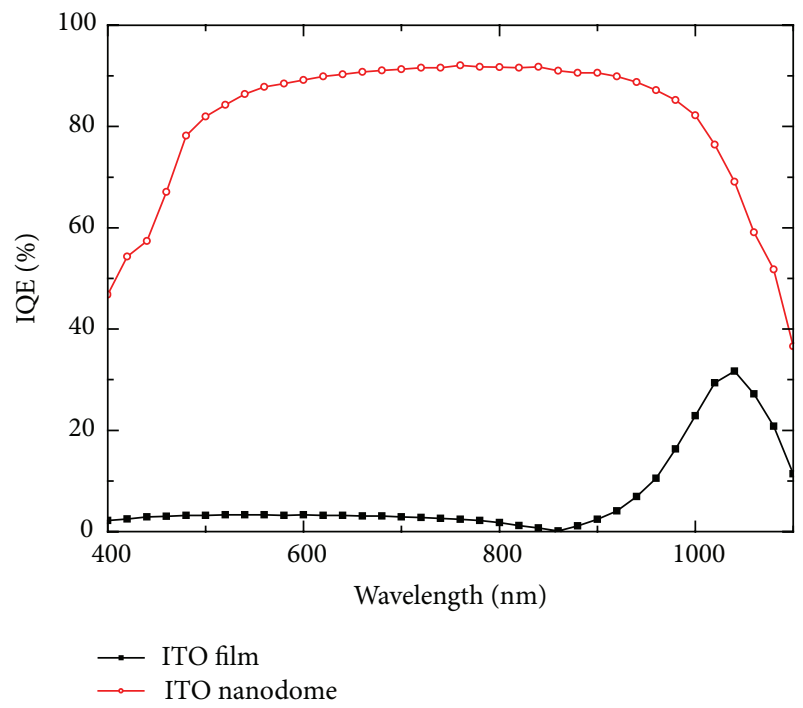

(a)

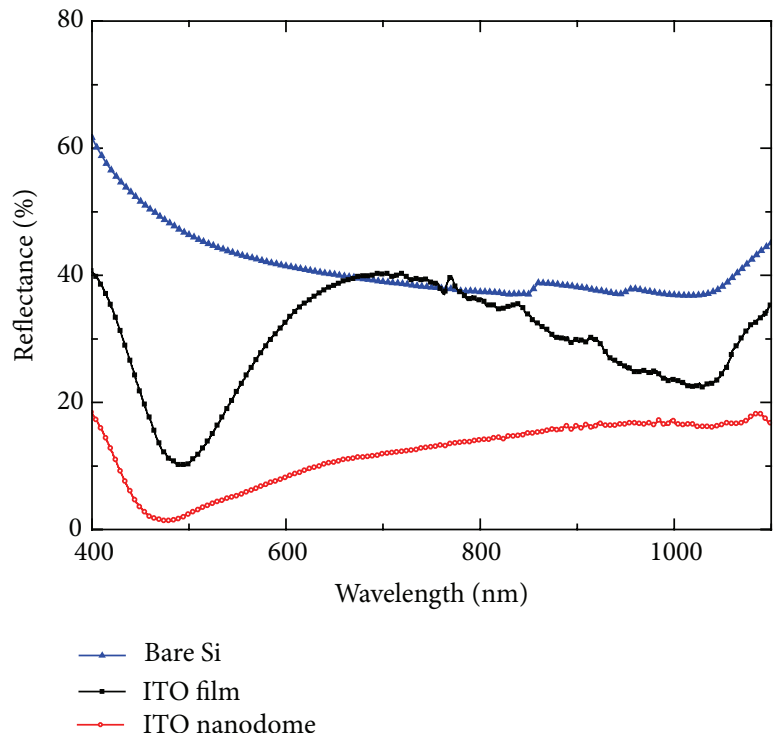

(b)

FIGURE 3: (a) Internal quantum efficiency and (b) reflectance profiles of planar and nanodome ITO films [6].

The single layer AZO and bilayer (AZO/ITO) samples exhibited more or less same behavior. This predicts that the contribution of ITO film in optical transparency is less within certain layer thickness. In contrast, the domination of ITO film is more prominent in electrical properties of AZO/ITO samples than AZO film. The properties of resistivity and mobility of AZO, ITO, and AZO/ITO films are shown in Figure 6. The single ITO film showed the highest mobility of $42 \mathrm{~cm}^{2} /$ Vs with the lowest resistivity of $1.53 \times$ $10^{-4} \Omega \mathrm{cm}$, while single AZO film had the lowest mobility of $15.4 \mathrm{~cm}^{2} /$ Vs with a higher resistivity of $9.23 \times 10^{-4} \Omega \mathrm{cm}$. But electrical resistivity and mobility, that is, $3.54 \times 10^{-4} \Omega \mathrm{cm}$ 


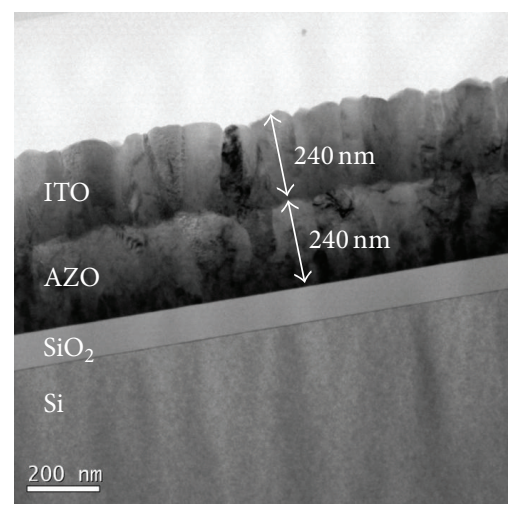

(a)

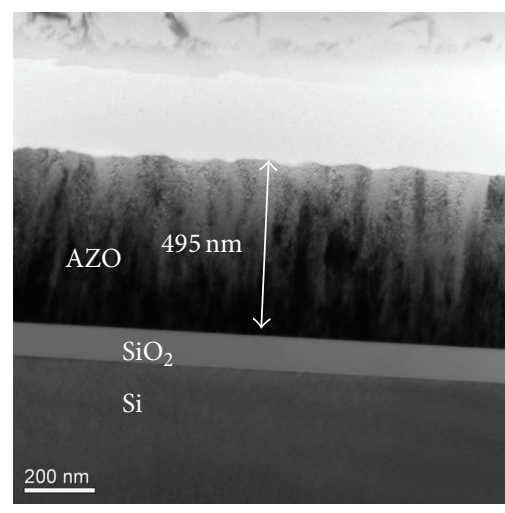

(b)

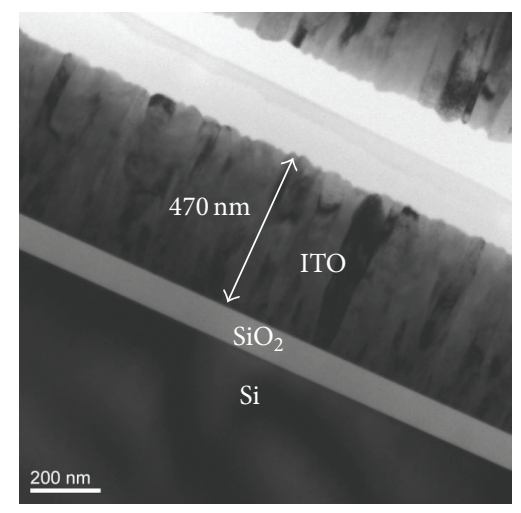

(c)

FIGURE 4: Low-magnification TEM images of (a) ITO/AZO, (b) AZO, and (c) ITO films [2].

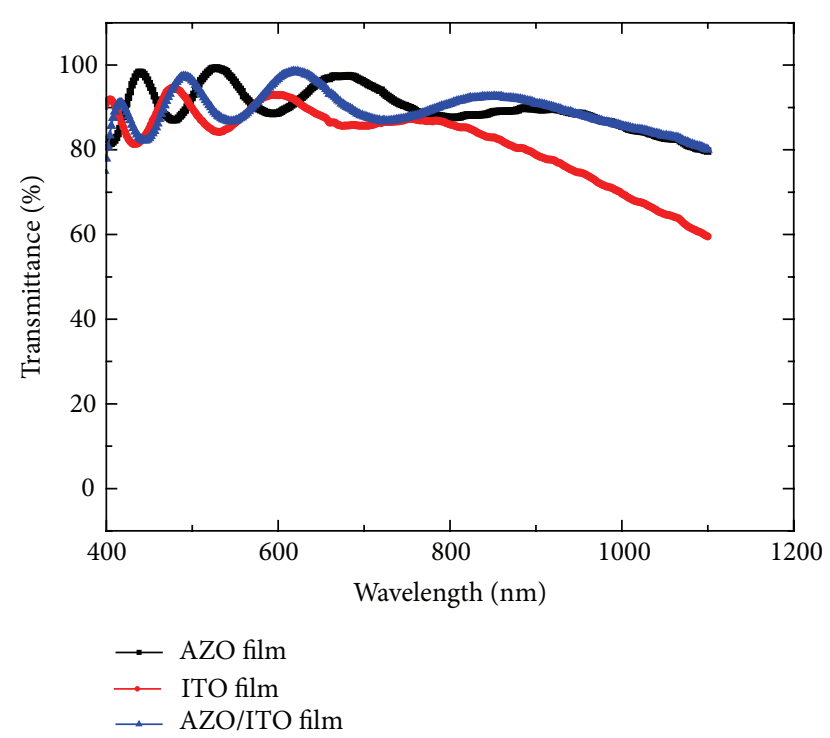

FIGURE 5: Optical transmittance spectra of AZO, ITO, and AZO/ITO films [12].

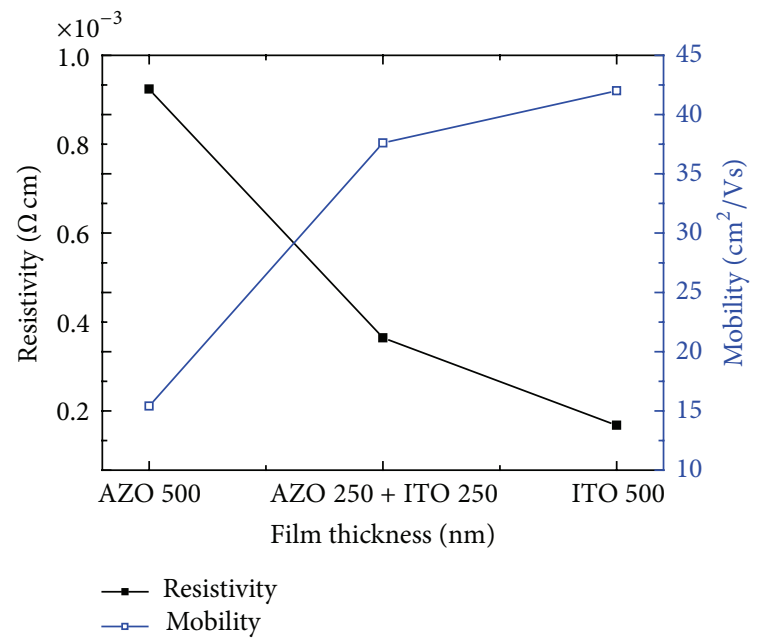

FIgURE 6: Electrical properties of AZO, AZO/ITO bilayer, and ITO films [12]. and $37.6 \mathrm{~cm}^{2} / \mathrm{Vs}$, respectively, improved in AZO/ITO double layers. These results provide the confidence that the electrical and optical properties of AZO/ITO films can be tuned by adjusting the layer thickness of single TCO film. Then the rectifying current in heterojunction devices mainly depends on the energy band gap of materials. The band gap values of AZO and ITO films are 3.37 and $3.8 \mathrm{eV}$, respectively. Larger band gap TCO material creates larger potential barrier for the electron to flow from junction to $\mathrm{n}$-Si.

Therefore, reduction of rectifying current took place in ITO/n-Si device. The enhanced current profile was achieved in ITO/AZO/n-Si device due to the formation of smaller potential barrier between $\mathrm{AZO}$ and $\mathrm{n}$-Si. In short, the results showed that $\mathrm{ITO} / \mathrm{AZO} / \mathrm{n}-\mathrm{Si}$ heterojunction photoelectric devices have reserved the advantageous properties of AZO and ITO films, that is, high transmittance and rectifying current of AZO layer and better electrical conductivity of ITO layer, to enhance and tune its own properties.

2.3. Patterned Substrates: SiNP. In the previous sections, the enhancement of electrical and optical properties of photoelectric devices by altering the structure of TCO layers was discussed. The properties of substrates used to prepare the devices also contribute much to the enhancement of efficiency in heterojunction devices. Si is the most commonly used substrate in all the photovoltaic cells and photoelectric applications. In recent years, researches around the world focused on enhancing the incident light utilization capacity of Si for cost-reduction purpose [13]. This can be achieved by reducing surface reflection of the incident light and enlarging the light-active surface region. The studies of $\mathrm{Si}$ nanowire (SiNW) [14-16] or Si nanopillar (SiNP) [17-19] for solar cell applications are having the feasibility to enlarge the lightactive surface region. The efficient light harvesting system by implementing SiNP has been demonstrated experimentally by Jee et al. [20]. SiNPs were created by lithography-free approach, thereby reducing the manufacturing cost. The ink containing $5 \mathrm{wt}$ \% Ag nanoparticles of diameters of $10-20 \mathrm{~nm}$ was spin-coated onto a cleaned p-Si substrate. Islands of Ag nanoparticles were then formed by subsequent annealing at 
$250^{\circ} \mathrm{C}$. When Si substrate with Ag islands has undergone the reactive ion etching (RIE) process, the zones of $\mathrm{p}$-Si substrate which are not covered by nanoscale islands of Ag were etched away deeply. Then the Ag residuals were also removed by nitric acid treatment resulting in the simultaneous formation of SiNP [21]. By adjusting annealing time duration, SiNP substrates with different nanopillar density were formed to understand the importance of density of pillars in the light harvesting activity. A thin AZO layer was deposited by cosputtering system around the SiNP and formed n-AZO/pSiNP abrupt junction. Another AZO film of thickness $500 \mathrm{~nm}$ was coated above this junction as transparent top contact layer as shown in Figure 7.

The refractive indices of air, $\mathrm{Si}$, and $\mathrm{ZnO}$ are 1, 4.1, and 2.4, respectively. Hence, AZO acts effectively as an intermediate layer between $\mathrm{Si}$ and air. The reflectance spectra of planar $\mathrm{Si}$, AZO-coated planar Si, SiNP, and AZO-coated SiNP were shown in Figure 8, which clearly shows the significant reduction of reflection in nanopillar structured $\mathrm{Si}$ compared to the other three substrates. Next to SiNP, it was AZO-coated SiNP structure in reduction of reflection. The $500 \mathrm{~nm}$ thick AZO film induces oscillations due to constructive and destructive interference at different wavelengths by multiple internal reflections $[19,22]$ resulting in reduction of reflection.

Due to less light-reflectance, the photocurrent in SiNP samples was improved. The increase of the photocurrent is proportional to the enlargement of surface area of nanopillar textured Si substrate. Therefore, higher current density was achieved from high density $\operatorname{SiNP}\left(5.45 \mathrm{~mA} / \mathrm{cm}^{2}\right)$ while planar Si sample showed current density of only $1.1 \mathrm{~mA} / \mathrm{cm}^{2}$. An attractive stuff in this research is that the thin $\mathrm{n}-\mathrm{AZO}$ coating on the $\mathrm{p}$-SiNP leads to the direct formation of a radial $\mathrm{n} / \mathrm{p}$ junction and the $500 \mathrm{~nm}$ thick $\mathrm{AZO}$ transparent electrode layer tied with the nanoscale $n / p$ photoelectric heterojunctions without any difficulties. This result promises to enhance the performance of conventional Si-based photoelectric devices with a cost effective design scheme.

2.4. Ag Nanoparticles Embedded TCO Layers. Quite recently, plasmonic solar cells have been on the keen interest in the photovoltaics researches [23]. A surface plasmon is a bound excitation on the surface of a metal produced by the interaction of light with free electrons [24]. Nanoparticles of metals such as Au and Ag can exhibit strong localized surface plasmon resonances (LSPRs) at UV, visible and near infrared (NIR) wavelengths [25]. The optical properties of metal nanoparticles can be tuned by changing their size or shape or by altering the local dielectric environment [26]. In recent years metal nanoparticles have been shown to improve the performance of photodiodes [27, 28], solar cells [29, 30], and LEDs [31]. Pillai et al. [29] demonstrated the large increase of photocurrent around the band-edge region for wafer-based silicon solar cells coated with silver nanoparticles. These gains are attributed to a reduction of surface reflectance and an increase of light trapping due to scattering by the metal nanoparticles.

As a next step of this progress, sandwiched layer of $\mathrm{Ag}$ nanoparticles (NPs) between AZO layers was incorporated

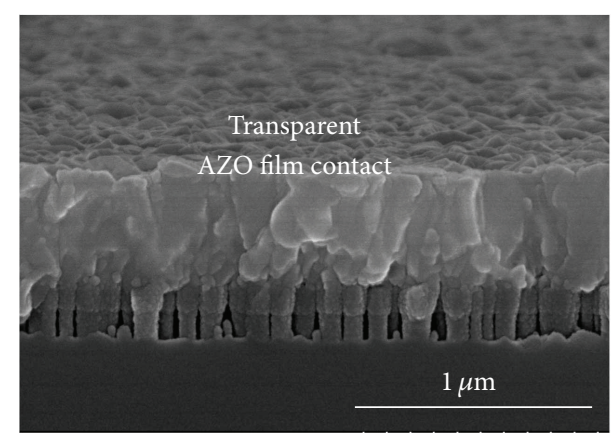

FIGURE 7: Cross-sectional SEM image of n-AZO/p-SiNP sample showing high density $\mathrm{Si}$ nanopillars with top AZO transparent electrode [20].

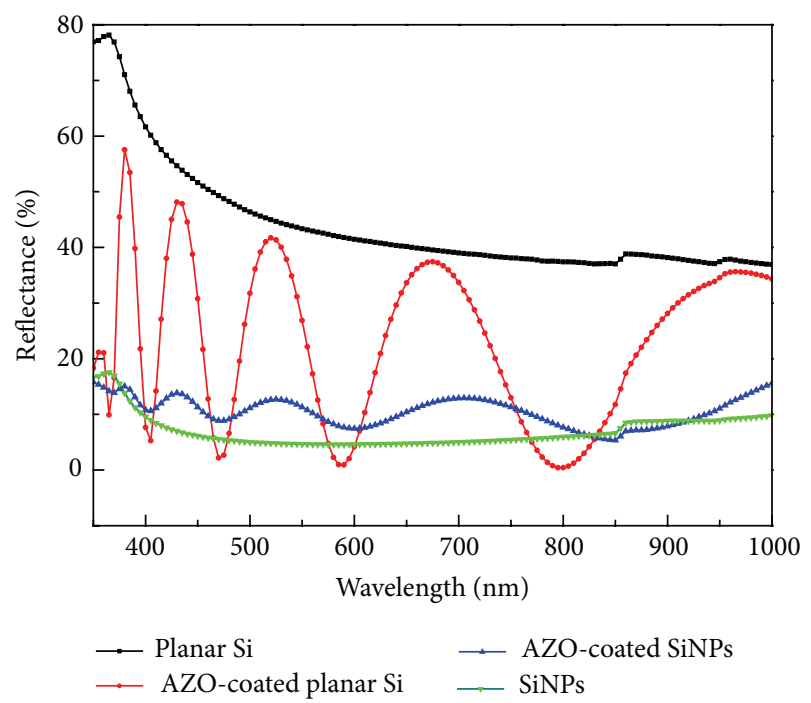

FIgUre 8: The reflectance profiles from planar Si, AZO-coated planar Si, SiNPs, and AZO-coated SiNPs. A comparative significant reduction of reflection was observed in AZO-coated SiNPs and nanopillar textured substrate [20].

on $\mathrm{n}$-Si substrate by Yun [32]. This isotype heterojunction solar cell exhibits highest quantum efficiency of $15 \%$ around $430 \mathrm{~nm}$. The schematic diagram of fabrication process of $\mathrm{n}-$ $\mathrm{AZO} / \mathrm{Ag} \mathrm{NPs} / \mathrm{n}-\mathrm{AZO} / \mathrm{n}-\mathrm{Si}$ solar cell is shown in Figure 9.

The layer thickness of AZO film which is in between nSi substrate and Ag NPs was varied by 10, 20, and $40 \mathrm{~nm}$, consequently adjusting the position of Ag NPs from $\mathrm{AZO} / \mathrm{Si}$ junction. During the deposition of top $\mathrm{AZO}$ film at $250^{\circ} \mathrm{C}$, Ag NPs positioned on $10 \mathrm{~nm}$ thick AZO was not able to withstand with its junction properties, resulting in a large leakage current and low fill factor. The Ag NPs positioned on $20 \mathrm{~nm}$ thick AZO film exhibited the enhanced quantum efficiency and $I-V$ characteristics which are shown in Figures 10 and 11, respectively.

The highest enhancement of $\mathrm{QE}$ was observed in the range of $400 \sim 500 \mathrm{~nm}$ of wavelength. In several reports, the resonance peak of Ag NPs was located at around $400 \mathrm{~nm}$ $[23,33]$. Here, it is at $470 \mathrm{~nm}$ (see Figure 10(b)) which was attributed to dielectric constant of the surrounding media 
(1) Si cleaning

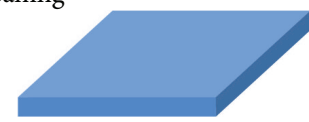

(2) AZO deposition

$(10,20$, and $40 \mathrm{~nm})$

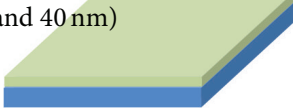

(3) Ag NPs decoration

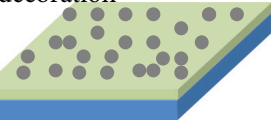

(4) AZO deposition (240 nm)

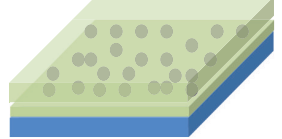

(8)

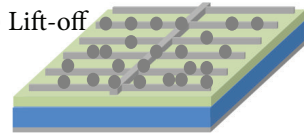

(7) $\mathrm{Al}$ deposit

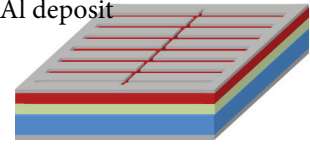

(6) Front grids patterning

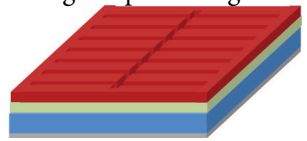

(5) Back Al deposit

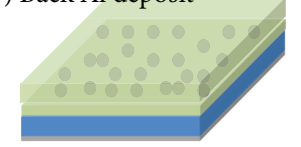

FIGURE 9: Schematic fabrication process of AZO/Ag NPs/AZO/Si solar cell structure with front and back contacts of $\mathrm{Al}$ [32].

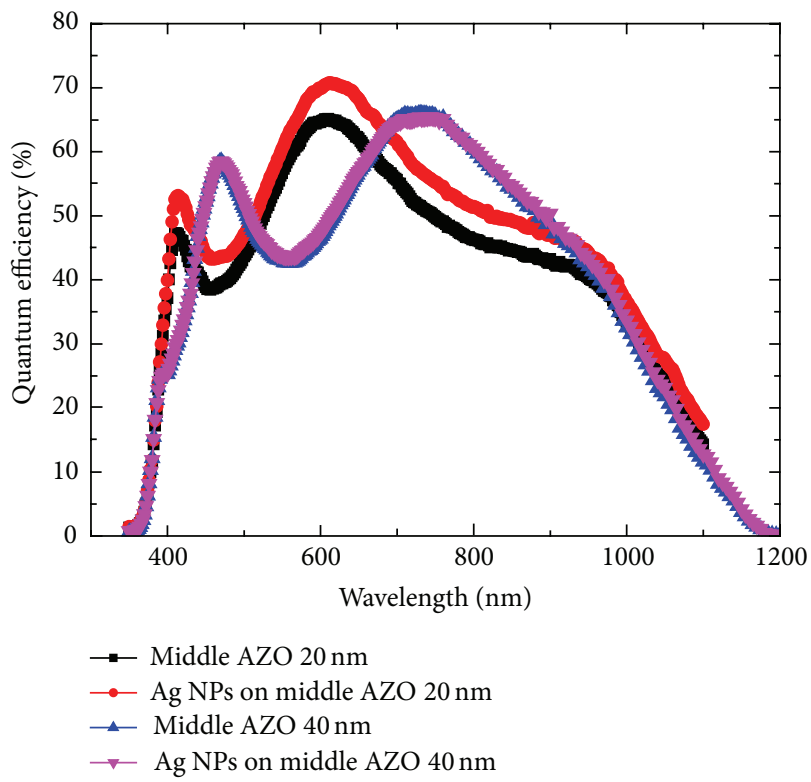

(a)

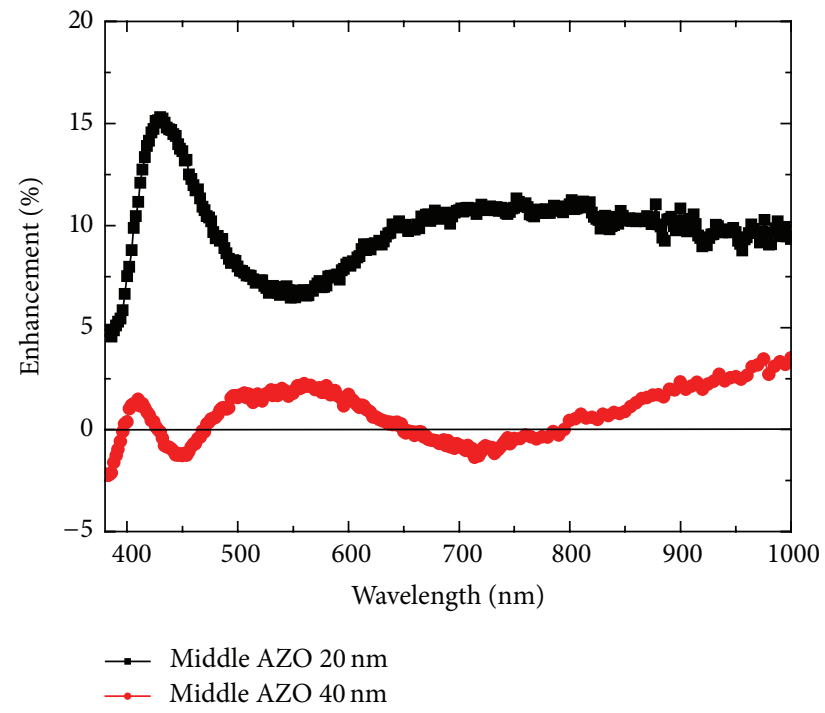

(b)

FIGURE 10: (a) Quantum efficiency spectra of AZO middle layers of 20, $40 \mathrm{~nm}$ thicknesses and the same layers coated with Ag nanoparticles; (b) Quantum efficiency enhancement of AZO layers of thicknesses of 20 and $40 \mathrm{~nm}$ without Ag NPs, showing QE mainly depends on thickness of middle AZO layer [32].

(AZO) of Ag NPs [23]. Calculated resonance peak of Ag NPs in AZO corresponds to the highest $\mathrm{QE}$ enhancement in the same range as shown in Figure 10(b). $I-V$ characteristics of sample where Ag NPs are positioned at $20 \mathrm{~nm}$ from junction are shown in Figure 11. From the above results, it is reported that Ag NPs located at $20-40 \mathrm{~nm}$ distance from a Si layer are most desirable for photovoltaic performance. A fabricated solar cell with Ag NPs buried in AZO at $20 \mathrm{~nm}$ distance from the junction between $\mathrm{Si}$ and AZO shows best power conversion efficiency. Highest efficiency was delivered with $0.36 \mathrm{~V}$ of $V_{\mathrm{oc}}, 28.3 \mathrm{~mA} / \mathrm{cm}^{2}$ of $J_{\mathrm{sc}}$, and $5.91 \%$ of conversion efficiency with QE enhancement of $15 \%$ around $430 \mathrm{~nm}$ and $5 \sim 10 \%$ within $600 \sim 1000 \mathrm{~nm}$.

The reason behind the highest efficiency of solar cell, in which Ag NPs were located at a distance of $20 \mathrm{~nm}$ from junction, is LSPR. As discussed earlier in this section, nanoparticles of $\mathrm{Ag}$ and $\mathrm{Au}$ are suitable materials for strong LSPR. When the incoming photons are incident on metal nanoparticles in the PV device, collective bound excitations will be produced on the surface due to the interaction of light with free electrons. These excited NPs are gradually decayed by means of scattering of photons which could be transferred 


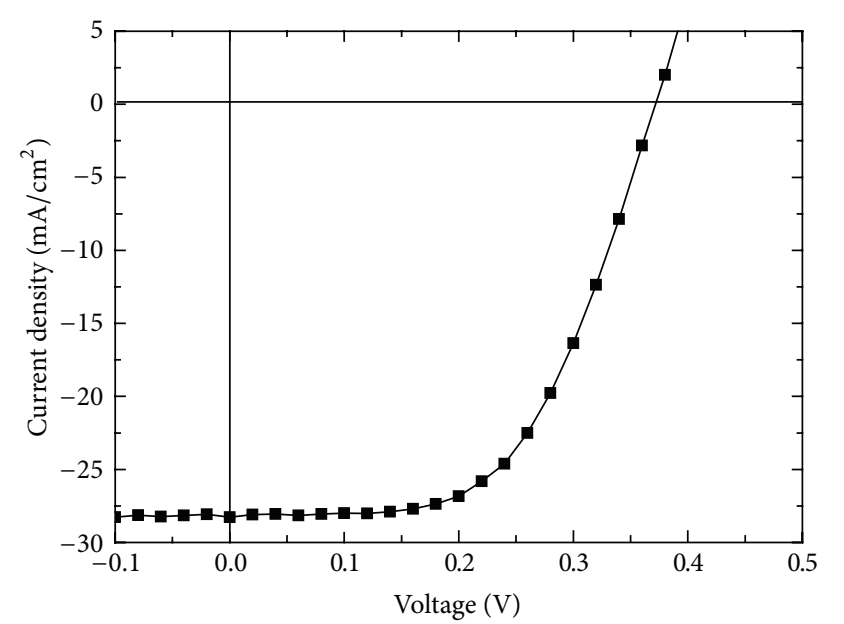

Optical input: AM1.5G, $100 \mathrm{~mW} / \mathrm{cm}^{2} \quad$ FF: 0.58 $V_{\mathrm{oc}}: 0.36 \mathrm{v}$ $J_{\text {sc }}: 28.3 \mathrm{~mA} / \mathrm{cm}^{2}$

Eff: $5.91 \%$

FIgURE 11: $I-V$ characteristics of fabricated solar cell where Ag NPs are positioned at $20 \mathrm{~nm}$ distance from $\mathrm{Si} / \mathrm{AZO}$ junction [32].

to depletion layer of the device. In AZO/Ag NPs/AZO/Si solar cells, when the distance between Ag NPs and junction is $20 \mathrm{~nm}$, the incident light energy is well transferred to the junction via surface plasmonic vibration. However, when this distance is increased to $40 \mathrm{~nm}$, the amount of energy transferred from Ag NPs to junction is decreased as shown in Figure 12.

Furthermore, Ag NPs are advantageous for surface plasmonics in solar cell because of low intrinsic losses. This leads to narrow LSP with high oscillator strengths and large optical field enhancements. The plasmonic structures of Ag NPs showed better performance in the wavelength range of 400$530 \mathrm{~nm}$, while $\mathrm{Au}$ NPs could be the good choice for longer wavelengths applications [32].

2.5. Variation of Physical Parameters. Besides structured TCO layers and substrates, the physical parameters such as thickness of layers, pressure, and temperature also play a vital role in determining the efficiency of heterojunction photoelectric devices. Among them, rapid thermal treatment of TCO electrodes has been studied by various research groups $[4,34,35]$ with the objective to provide the quality rectifying junctions between ITO film and Si substrate. An interfacial layer, between the ITO film and the Si substrate, is substantially affected by thermal treatment, which is essential for the performances of photodiodes. The formation of interfacial oxide at the junction and spontaneous change in the thickness of oxide layer with respect to temperature were thoroughly studied in the research work of Kim et al. [4]. ITO layer of $200 \mathrm{~nm}$ thickness was deposited on p-Si substrates by DC sputtering method. Then, the samples were treated with rapid thermal annealing process at 300 and $600^{\circ} \mathrm{C}$ for $10 \mathrm{~min}$ under vacuum condition. The thickness of interfacial $\mathrm{SiO}_{x}$ layer is increasing with increasing RTA temperature. This is clearly shown (Figures 13(a)-13(f)) in the TEM images

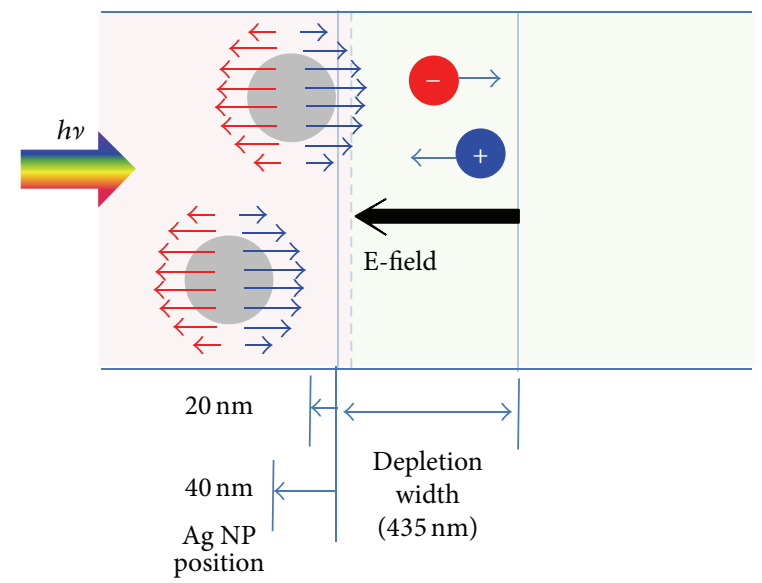

FIGURE 12: Schematic of localized surface plasmon (LSP) energy transferred from Ag NPs directly into the depletion layer [32].

of ITO-RT (room temperature), ITO- $300^{\circ} \mathrm{C}$ and ITO- $600^{\circ} \mathrm{C}$ samples. ITO-RT shows an interface thickness of $1.3 \mathrm{~nm}$, which is thicker than the usual $0.2-0.6 \mathrm{~nm}$ native oxide layer. This is attributed to the formation of a $\mathrm{SiO}_{x}$ layer by the implantation of negatively charged oxygen ions into the $\mathrm{Si}$ during the ITO deposition [36].

After RTA processes, the interface grew up to $1.4 \mathrm{~nm}$ for ITO- $300^{\circ} \mathrm{C}$ and $1.6 \mathrm{~nm}$ for ITO- $600^{\circ} \mathrm{C}$. The depth profiles of samples were recorded as shown in Figures 13(g)-13(i). For the sample ITO-RT, clear boundary between $\mathrm{p}$-Si and ITO film is shown at $200 \mathrm{~nm}$ depth, while the penetration of $\mathrm{Si}$ and $\mathrm{Sn}$ into the opposite region due to increasing temperature in the samples ITO- $300^{\circ} \mathrm{C}$ and ITO $-600^{\circ} \mathrm{C}$ was observed. This clearly shows the solid-state oxidation reaction of $\mathrm{Si}$ to ITO [36]. Limited $\mathrm{Si}$ diffusion occurs through the $\mathrm{SiO}_{x}$ and $\mathrm{Si}$ continuously finds oxygen at interface, incurred by the decomposition of $\mathrm{SnO}_{2}$ [37], resulting in the growth of the $\mathrm{SiO}_{x}$ layer. Figures 14(a) and 14(b) show the electrical resistivity and transmittance of the samples.

Excellent reduction of resistivity of $2.94 \times 10^{-4} \Omega \mathrm{cm}$ and enhanced transmittance value of $89.2 \%$ were observed for the sample ITO- $600^{\circ} \mathrm{C}$. This condition is reversed when analyzing $I-V$ characteristics and internal quantum efficiency of the samples. Here, quality of rectifying junction and the carrier collection performance (see Figure 15) of ITO-300 ${ }^{\circ} \mathrm{C}$ sample are surprisingly enhanced when comparing those qualities with ITO-RT and ITO- $600^{\circ} \mathrm{C}$ samples. As temperature increased, interfacial layer becomes so thicker and that degraded the photoresponses of ITO/Si heterojunction devices. This is the reason for exhibiting different behaviors by ITO- $600^{\circ} \mathrm{C}$ sample in optical and electric characteristics. This result suggested that RTA is an effective method to establish quality heterojunction between ITO film and Si substrate at reduced thermal budget.

Kim et al. [38] have reported a new approach to increase the efficiency of usual ITO/p-Si heterojunction devices. By varying the number of fingers in the front Ag electrode, the efficiency of the devices has been measured. The 4-finger design was significantly enhanced by the current density of 


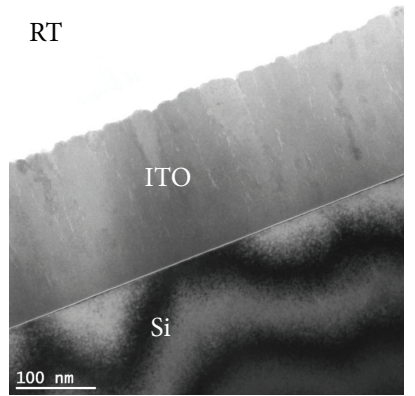

(a)

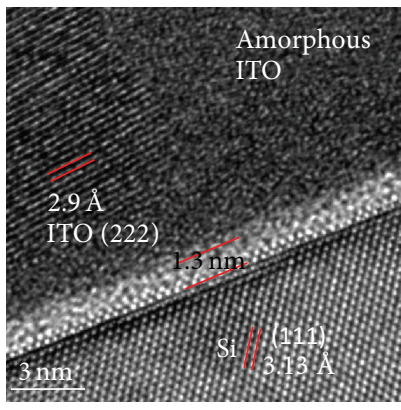

(d)

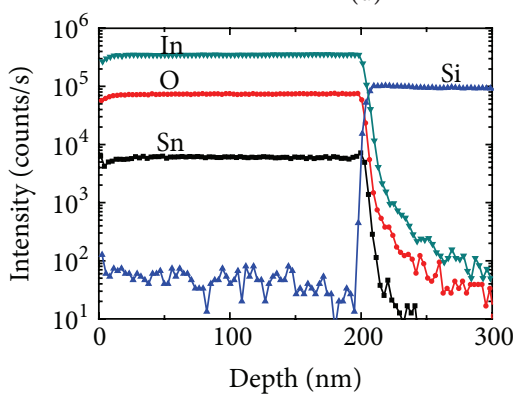

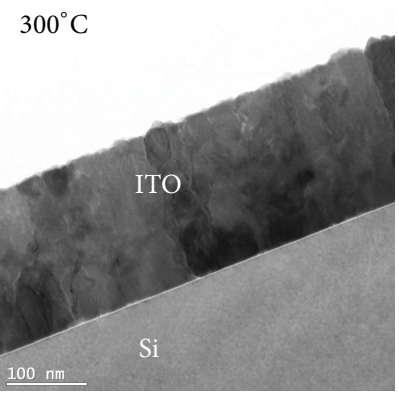

(b)

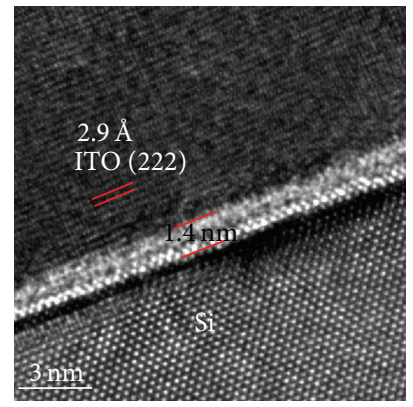

(e)
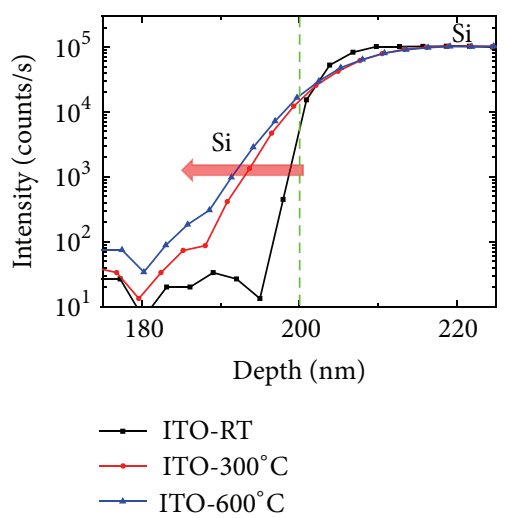

(h)

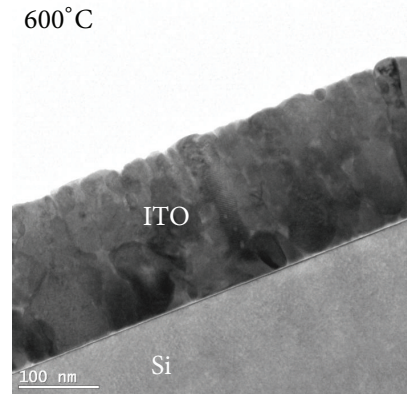

(c)

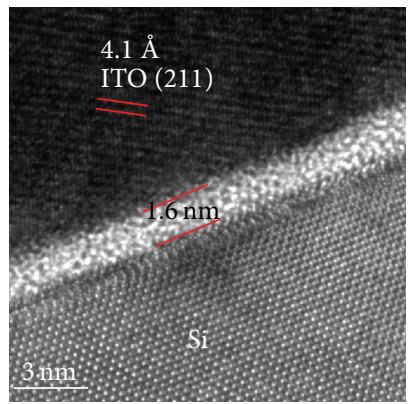

(f)
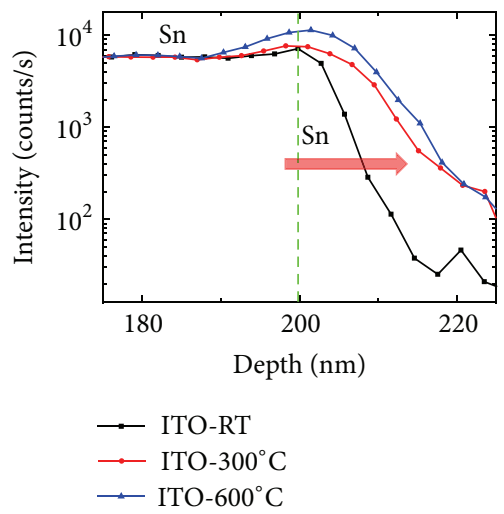

(i)

Figure 13: (a)-(c) Low-resolution TEM images of ITO-RT, ITO- $300^{\circ} \mathrm{C}$, and ITO- $600^{\circ} \mathrm{C}$ samples. (d)-(f) High-resolution TEM images of ITO-RT, ITO- $300^{\circ} \mathrm{C}$, and ITO- $600^{\circ} \mathrm{C}$ samples. (g)-(i) Depth profiles of prepared samples (g) for ITO-RT, (h) showing Si signals, and (i) showing Sn signals of ITO-RT, ITO- $300^{\circ} \mathrm{C}$, and ITO- $600^{\circ} \mathrm{C}$ samples [4].

$38.01 \mathrm{~mA} / \mathrm{cm}^{2}$ and efficiency of $16.7 \%$. The shading loss of this device is only $0.94 \%$ whereas it is $4.19 \%$ in the device where 20-finger design was used. This is possible due to benefit of the electrically conductive and optically transparent conductors.

2.6. Other TCO Materials. In 1907, Badekar [39] reported the first transparent conducting thin films of cadmium oxide (CdO). Since then many research works were done in the field of TCO materials and as a consequence of this, thousands of appropriate literature resources were published [40]. A specific advantage of the TCOs, compared to their metalbased counterparts, is the chemical and mechanical stability, which allows their use on displays as well as in PV devices. Several useful reviews of TCOs have already been published
[41-46]. As discussed earlier, ITO and AZO are widely used TCOs due to their excellent properties and suitability in optoelectronic devices. These tin and zinc oxides have been doped with many other metals such as copper, silver, gallium, magnesium, cadmium, indium, scandium, yttrium, cobalt, manganese, chrome, and boron [46-49] to form new TCO materials. Other than ITO and AZO, there were many TCO materials that have been studied and applied successfully for various applications. In particular, $\mathrm{SnO}_{2}, \mathrm{In}_{2} \mathrm{O}_{3}, \mathrm{ZnO}$, and CdO films are important binary compound TCO materials in the recent researches [50]. There are numerous ternary compounds reported frequently, among them $\mathrm{Zn}_{2} \mathrm{SnO}_{4}$ [51], $\mathrm{MgIn}_{2} \mathrm{O}_{4}$ [52], $\mathrm{CdSb}_{2} \mathrm{O}_{6}: \mathrm{Y}$ [53], $\mathrm{ZnSnO}_{3}$ [54], $\mathrm{GaInO}_{3}$ [55], $\mathrm{Zn}_{2} \mathrm{In}_{2} \mathrm{O}_{5}$ [56], and $\operatorname{In}_{4} \mathrm{Sn}_{3} \mathrm{O}_{12}$ [57] are the most cited materials. Each of the binary and ternary TCO compounds has 


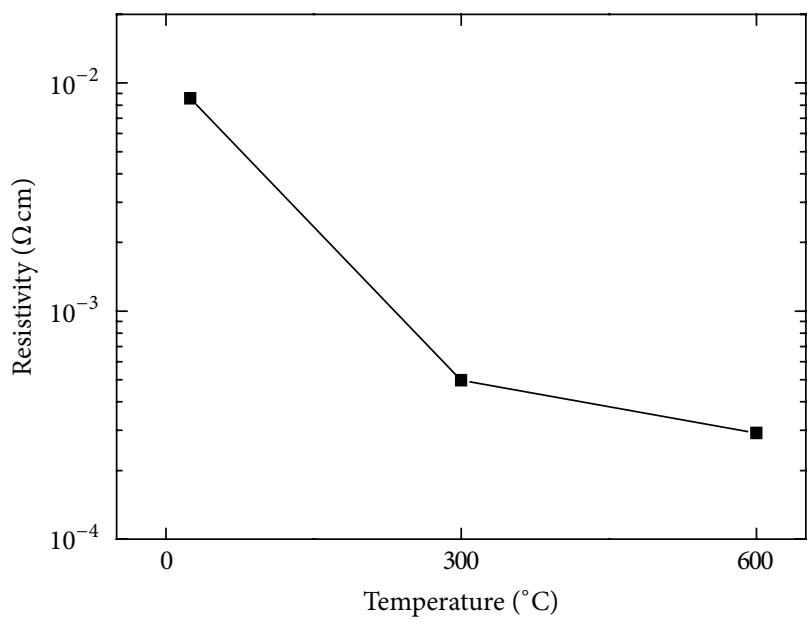

(a)

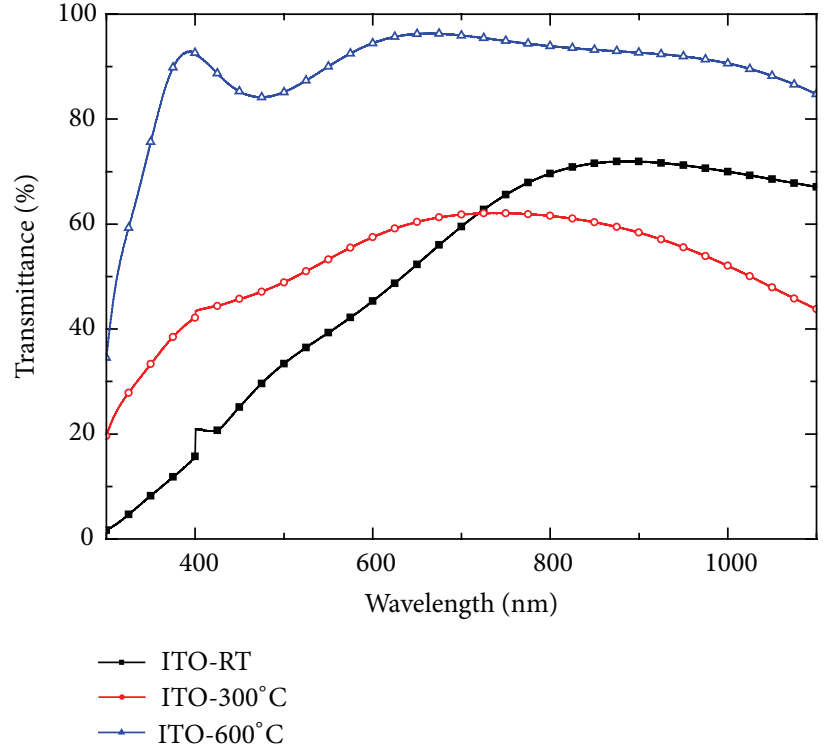

(b)

FIGURE 14: (a) Resistivity and (b) optical transmittance values of ITO-RT, ITO-300 ${ }^{\circ} \mathrm{C}$, and ITO-600 ${ }^{\circ} \mathrm{C}$ samples [4].

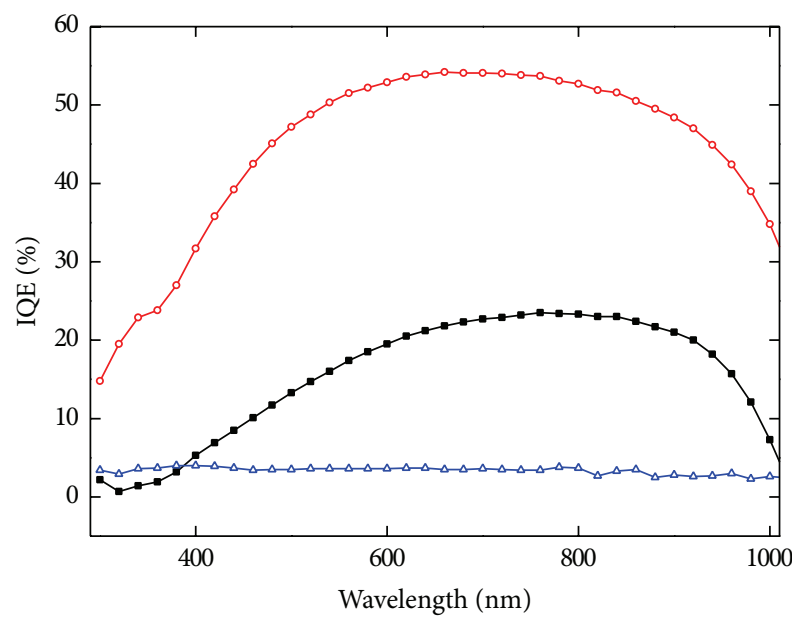

$\longrightarrow$ ITO-RT
$\multimap$ ITO- $300^{\circ} \mathrm{C}$
$\multimap$ ITO- $6000^{\circ} \mathrm{C}$

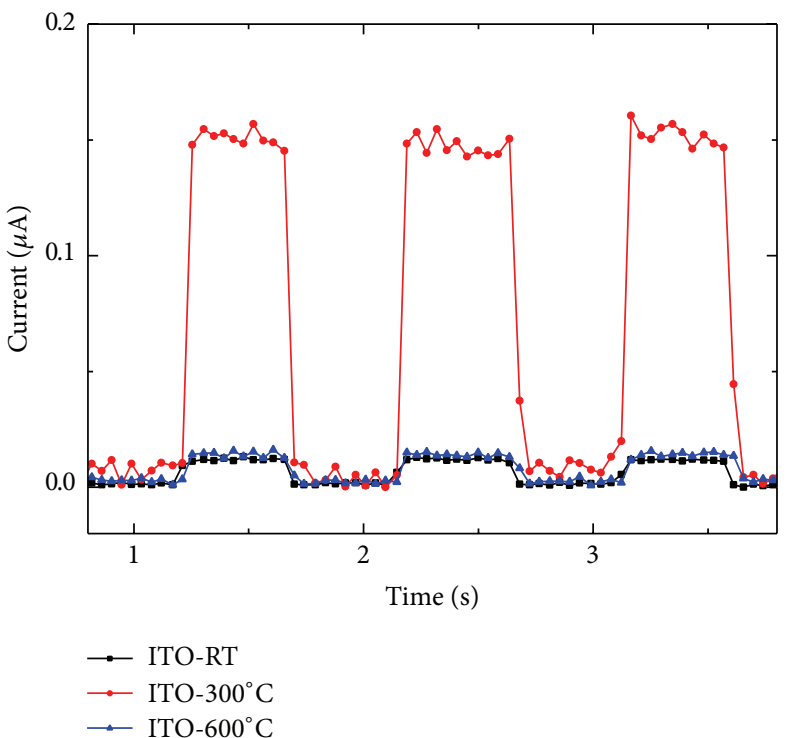

(b)

FIGURE 15: (a) IQE profile and (b) photoresponses at wavelength of $350 \mathrm{~nm}$ of ITO-RT, ITO- $300^{\circ} \mathrm{C}$, and ITO-600 ${ }^{\circ} \mathrm{C}$ samples [4].

its own property and characteristics. In particular, ITO films are used for increasing conductivity, AZO for transmittance, $\mathrm{ZnRh}_{2} \mathrm{O}_{4}$ for open-shell transition metal cation [58], $\mathrm{Ga}_{2} \mathrm{O}_{3}$ in deep-ultraviolet region [59], $\mathrm{CuInO}_{2}$ [60] for transparent oxide FET based on single-crystalline, and $\mathrm{InGaO}_{3}(\mathrm{ZnO})_{5}$ for [61] UV-light emitting diode [62].

From the reviews, it is suggested that the properties of a heterojunction device can be enhanced if the structures of substrates, TCO layers, and physical parameters associated with device fabrication are appropriately modulated. Moreover, it creates the clear path for the researchers for their subsequent level of research in heterojunction photoelectric devices.

\section{Advantages and Features of Heterojunction Devices}

The devices working based on photoelectric effect, in which light energy is converted into electricity, are termed as photoelectric devices. In the first generation photoelectric devices, bulk crystalline Si modules were used. Due to 
increased demand of $\mathrm{Si}$ in the energy markets, the cost of clean energy technologies tremendously increased. Then, the energy sectors focused on most cost efficient technologies in terms of reducing cost. The two main ideas to cut down the cost of photoelectric devices were increasing efficiency of devices and decreasing their cost per unit energy production. The second generation devices which were designed with thin film technologies consume less amount of Si-material and are cost effective. And, many alternate approaches have been practicing by research groups and industries to develop low cost and high efficient devices. The pioneered and effective approaches were discussed elaborately in the previous sections. The major advantages of the techniques involved in heterojunction devices are discussed here. Primarily, TCOs are exceptional materials which can play multirole in a device. Hence, they have been widely used in photoelectric devices [12] which require a transparent electrode to transport the light signals. In heterojunction devices, ITO films act as an antireflection coating and as well as transparent conductor. It increases the advantages of reduction in recombination for a light-doped emitter solar cell. Moreover, the structured TCO films collect more photogenerated carriers, inducing an enhanced current value and thereby increasing efficiency. In general, the collection and separation of charge carriers in the discussed heterojunction devices have quantitatively increased. For the solar cell performances, it is important to form a quality junction; otherwise the PV effect will be faded away by recombination in advance of collecting photogenerated carriers. The AZO/n-Si junction can separate the carriers and collect them efficiently at the shallow region from Si surface. This design could be furthermore enhanced by incorporating LSP phenomena. In 3D ITO domes and dots structure, each nanodome was electrically separated from the neighboring nanodomes. This separation effectively transferred the charge carrier from Si substrate to the front $\mathrm{Al}$ electrode. Moreover, carrier collection is investigated from the measurement of IQE and EQE. In the PV devices where $\mathrm{Si}$ nanopillars were employed, the enlarged light-active region increased the collection of photogenerated carriers. One of the most feasible approaches for cost reduction is to improve the utilization of incident light in the $\mathrm{Si}$ absorber. This is achieved by implementing SiNPs which were fabricated through lithography-free patterning, with AZO film in photoelectric devices. The enlargement of the $3 \mathrm{D}$ light-active surface has strong potential to enhance the performance of conventional Si-based photoelectric devices with cost effective design including films, nanowires, nanotubes, nanoparticles, and nanodomes $[6,12,20,63-66]$. The ITO nanodome structures added further optical benefit via significant reduction in the reflection. Compared to planar ITO film devices, ITO nanodomes showed high response to incident light. Therefore, from the aspect of design, a three-dimensional entity, present in either TCO layers or Si substrate, shows improved photoresponse due to the enhanced light-reactive surface area [5] that stems from the reduced light reflection at the surface $[67,68]$. The well-versed optical properties of AZO and electrical properties of ITO could be combined in AZO/ITO bilayer to enhance the overall performance of photoelectric devices. In heterojunction devices, the front $\mathrm{Ag}$ electrodes can be used effetely to reduce the shading loss. A systematic transmission line method suggests an optimum design of the ITO-Ag front electrode. As the light transparent surface on a front surface increases, more photon energy penetrates into a light absorber through a front contact and thus generates more electron-hole carriers. Semiconductors with metal nanoparticles increased light trapping capacity of devices via plasmonic oscillations. In recent researches, Ag nanoparticles sandwiched between AZO layers and dye sensitized solar cells (DSSCs) utilizing $\mathrm{SiO}_{2}$ and $\mathrm{TiO}_{2}$ encapsulated gold nanoparticles (Au NPs) attracted much attention for their enormous performance in formation and process of devices $[34,69]$. The combination of AZO thin film and Ag NPs can improve the photovoltaic performance of $\mathrm{AZO} / \mathrm{Si}$ heterostructure solar cells by utilizing both light management and electric power management. In spite of all these advantages, there are few limitations in using TCO materials. They are as follows: the transmittance of all TCO materials is limited in the infrared wavelength region and they are brittle in nature $[70,71]$. As a result, alternatives for TCOs such as thin metal sheets, graphene, and carbon nanotubes have been intensively studied [71].

\section{Conclusions}

The advanced progress proceeding in the fabrication of heterojunction photoelectric devices and their advantages are analyzed and compared with an objective to explore novel techniques to enhance the device property at reduced budget. It is clearly emphasized that how the properties of ITO and AZO films could be enhanced in a heterojunction device by adjusting its structure/shape, layer thickness, and rapid annealing temperature. Plasmonic light trapping effect, in order to increase the energy harvesting nature of photoelectric devices, is explained in detail from n-AZO/Ag NPs/nAZO/n-Si type solar cell. Photolithography-free technique to fabricate Si nanopillar substrate is also discussed. The importance of the structure and area of front electrodes and the effect of temperature on the junction between ITO film and $\mathrm{Si}$ substrate are given on account of this review. This work would be helpful for the researchers to take up their research on heterojunction photoelectric devices to the next progressive ground.

\section{Conflict of Interests}

The authors declare that there is no conflict of interests regarding the publication of this paper.

\section{Authors' Contribution}

M. Melvin David Kumar and Ju-Hyung Yun equally contributed to this work.

\section{Acknowledgments}

The authors acknowledge the financial support of Korea Institute of Energy Technology Evaluation and Planning, 
in a Grant funded by the Ministry of Knowledge and Economy (KETEP-20133030011000). M. Melvin David Kumar and Ju-Hyung Yun equally contributed to this work.

\section{References}

[1] R. F. Service, "Is it time to shoot for the sun?" Science, vol. 309, no. 5734, pp. 548-551, 2005.

[2] J.-H. Yun, J. Kim, Y. C. Park, S.-J. Moon, and W. A. Anderson, "Double transparent conducting layers for Si photovoltaics," Thin Solid Films, vol. 547, pp. 17-21, 2013.

[3] T. Koida, H. Fujiwara, and M. Kondo, "High-mobility hydrogen-doped In2 O3 transparent conductive oxide for a-Si:H/c-Si heterojunction solar cells," Solar Energy Materials and Solar Cells, vol. 93, no. 6-7, pp. 851-854, 2009.

[4] H. Kim, S.-H. Hong, Y. Chang Park, J. Lee, C.-H. Jeon, and J. Kim, "Rapid thermal-treated transparent electrode for photodiode applications," Materials Letters, vol. 115, pp. 45-48, 2014.

[5] J. Kim, M. Kim, H. Kim et al., "Effective light management of three-dimensionally patterned transparent conductive oxide layers," Applied Physics Letters, vol. 101, no. 14, Article ID 143904 , 2012.

[6] S.-H. Hong, J.-H. Yun, H.-H. Park, and J. Kim, "Nanodomepatterned transparent conductor for highly responsive photoelectric device," Applied Physics Letters, vol. 103, no. 15, Article ID 153504, 2013.

[7] H. Liu, V. Avrutin, N. Izyumskaya, Ü. Özgr, and H. Morkoç, "Transparent conducting oxides for electrode applications in light emitting and absorbing devices," Superlattices and Microstructures, vol. 48, no. 5, pp. 458-484, 2010.

[8] D.-S. Liu, C.-S. Sheu, C.-T. Lee, and C.-H. Lin, "Thermal stability of indium tin oxide thin films co-sputtered with zinc oxide," Thin Solid Films, vol. 516, no. 10, pp. 3196-3203, 2008.

[9] D.-W. Kang, S.-H. Kuk, K.-S. Ji, H.-M. Lee, and M.-K. Han, "Effects of ITO precursor thickness on transparent conductive Al doped ZnO film for solar cell applications," Solar Energy Materials and Solar Cells, vol. 95, no. 1, pp. 138-141, 2011.

[10] S. S. Shinde and K. Y. Rajpure, "Fast response ultraviolet Ga-doped $\mathrm{ZnO}$ based photoconductive detector," Materials Research Bulletin, vol. 46, no. 10, pp. 1734-1737, 2011.

[11] Y. Yang, L. Wang, H. Yan, S. Jin, T. J. Marks, and S. Li, "Highly transparent and conductive double-layer oxide thin films as anodes for organic light-emitting diodes," Applied Physics Letters, vol. 89, no. 5, Article ID 051116, 2006.

[12] J.-H. Yun and J. Kim, "Double transparent conducting oxide films for photoelectric devices," Materials Letters, vol. 70, pp. 46, 2012.

[13] S. E. Han and G. Chen, "Toward the lambertian limit of light trapping in thin nanostructured silicon solar cells," Nano Letters, vol. 10, no. 11, pp. 4692-4696, 2010.

[14] B. Tian, X. Zheng, T. J. Kempa et al., "Coaxial silicon nanowires as solar cells and nanoelectronic power sources," Nature, vol. 449, no. 7164, pp. 885-889, 2007.

[15] S.-W. Jee, J. Kim, J.-Y. Jung et al., "Ni-catalyzed growth of silicon wire arrays for a Schottky diode," Applied Physics Letters, vol. 97, no. 4, Article ID 042103, 2010.

[16] S.-J. Park, S.-W. Lee, K.-J. Lee et al., "An antireflective nanostructure array fabricated by nanosilver colloidal lithography on a silicon substrate," Nanoscale Research Letters, vol. 5, no. 10, pp. 1570-1577, 2010.
[17] B. H. Kong, M. K. Choi, H. K. Cho, J. H. Kim, S. Baek, and J.-H. Lee, "Conformal coating of conductive $\mathrm{ZnO}$ :Al films as transparent electrodes on high aspect ratio Si microrods," Electrochemical and Solid-State Letters, vol. 13, no. 2, pp. K12K14, 2010.

[18] J.-Y. Jung, Z. Guo, S.-W. Jee et al., "A waferscale Si wire solar cell using radial and bulk p-n junctions," Nanotechnology, vol. 21, no. 44, Article ID 445303, 2010.

[19] C. Cheng, T.-L. Wang, L. Feng et al., "Vertically aligned $\mathrm{ZnO} /$ amorphous-Si core-shell heterostructured nanowire arrays," Nanotechnology, vol. 21, no. 47, Article ID 475703, 2010.

[20] S.-W. Jee, S.-J. Park, J. Kim et al., "Efficient three-dimensional nanostructured photoelectric device by $\mathrm{Al}-\mathrm{ZnO}$ coating on lithography-free patterned Si nanopillars," Applied Physics Letters, vol. 99, no. 5, Article ID 053118, 2011.

[21] D. Wang, R. Ji, S. Du, A. Albrecht, and P. Schaaf, "Ordered arrays of nanoporous silicon nanopillars and silicon nanopillars with nanoporous shells," Nanoscale Research Letters, vol. 8, no. 1, pp. $1-9,2013$.

[22] J. W. Leem, Y. M. Song, Y. T. Lee, and J. S. Yu, "Antireflective properties of AZO subwavelength gratings patterned by holographic lithography," Applied Physics B: Lasers and Optics, vol. 99, no. 4, pp. 695-700, 2010.

[23] K. R. Catchpole and A. Polman, "Plasmonic solar cells," Optics Express, vol. 16, no. 26, pp. 21793-21800, 2008.

[24] W. L. Barnes, A. Dereux, and T. W. Ebbesen, "Surface plasmon subwavelength optics," Nature, vol. 424, no. 6950, pp. 824-830, 2003.

[25] E. Hutter and J. H. Fendler, "Exploitation of localized surface plasmon resonance," Advanced Materials, vol. 16, no. 19, pp. 1685-1706, 2004.

[26] K. L. Kelly, E. Coronado, L. L. Zhao, and G. C. Schatz, "The optical properties of metal nanoparticles: the influence of size, shape, and dielectric environment," Journal of Physical Chemistry B, vol. 107, no. 3, pp. 668-677, 2003.

[27] H. R. Stuart and D. G. Hall, "Island size effects in nanoparticleenhanced photodetectors," Applied Physics Letters, vol. 73, no. 26, pp. 3815-3817, 1998.

[28] S. H. Lim, W. Mar, P. Matheu, D. Derkacs, and E. T. Yu, "Photocurrent spectroscopy of optical absorption enhancement in silicon photodiodes via scattering from surface plasmon polaritons in gold nanoparticles," Journal of Applied Physics, vol. 101, no. 10, Article ID 104309, 2007.

[29] S. Pillai, K. R. Catchpole, T. Trupke, and M. A. Green, "Surface plasmon enhanced silicon solar cells," Journal of Applied Physics, vol. 101, no. 9, Article ID 093105, 2007.

[30] M. Westphalen, U. Kreibig, J. Rostalski, H. Lüth, and D. Meissner, "Metal cluster enhanced organic solar cells," Solar Energy Materials and Solar Cells, vol. 61, no. 1, pp. 97-105, 2000.

[31] S. Pillai, K. R. Catchpole, T. Trupke, G. Zhang, J. Zhao, and M. A. Green, "Enhanced emission from Si-based light-emitting diodes using surface plasmons," Applied Physics Letters, vol. 88, no. 16, Article ID 161102, 2006.

[32] J.-H. Yun, ZnO thin films and nanostructures for optoelectronic applications [Ph.D. thesis], University at Buffalo, State University of New York, Buffalo, NY, USA, 2013.

[33] X. Chen, B. Jia, J. K. Saha et al., "Broadband enhancement in thin-film amorphous silicon solar cells enabled by nucleated silver nanoparticles," Nano Letters, vol. 12, no. 5, pp. 2187-2192, 2012. 
[34] W.-J. Lee, C.-R. Cho, K.-M. Cho, and S.-Y. Jeong, "Rapid thermal annealing effect of Al-doped $\mathrm{ZnO}$ thin films," Journal of the Korean Physical Society, vol. 47, no. 2, pp. S296-S299, 2005.

[35] M.-C. Jun and J.-H. Koh, "Effects of annealing temperature on properties of al-doped zno thin films prepared by sol-gel dipcoating," Journal of Electrical Engineering and Technology, vol. 8, no. 1, pp. 163-167, 2013.

[36] C. W. Ow-Yang, Y. Shigesato, and D. C. Paine, "Interfacial stability of an indium tin oxide thin film deposited on $\mathrm{Si}$ and Si0.85Ge0.15," Journal of Applied Physics, vol. 88, no. 6, pp. 3717$3724,2000$.

[37] S. M. Goodnick, J. F. Wager, and C. W. Wilmsen, "Thermal degradation of indium-tin-oxide/ p-silicon solar cells," Journal of Applied Physics, vol. 51, no. 1, pp. 527-531, 1980.

[38] M. Kim, J. Kim, H. Kim et al., "Optimization of transparent conductor-embedding front electrodes for efficient light management," Current Applied Physics, vol. 13, no. 5, pp. 808-813, 2013.

[39] K. Badekar, "Electrical conductivity and thermoelectric power of some heavy metal compounds," Annalen der Physik (Leipzig), vol. 22, p. 749, 1907.

[40] T. Minami, "New n-type transparent conducting oxides," MRS Bulletin, vol. 25, no. 8, pp. 38-44, 2000.

[41] D. S. Ginley and C. Bright, "Transparent conducting oxides," MRS Bulletin, vol. 25, no. 8, pp. 15-18, 2000.

[42] T. Minami, "Transparent conducting oxide semiconductors for transparent electrodes," Semiconductor Science and Technology, vol. 20, no. 4, pp. S35-S44, 2005.

[43] P. P. Edwards, A. Porch, M. O. Jones, D. V. Morgan, and R. M. Perks, "Basic materials physics of transparent conducting oxides," Dalton Transactions, no. 19, pp. 2995-3002, 2004.

[44] D. W. Stefaan, D. Antoine, Z. C. Holman, and B. Christophe, "High-efficiency silicon heterojunction solar cells: a review," Green, vol. 2, pp. 7-24, 2012.

[45] C. G. Granqvist, "Transparent conductors as solar energy materials: a panoramic review," Solar Energy Materials and Solar Cells, vol. 91, no. 17, pp. 1529-1598, 2007.

[46] S. Andreas, "Transparent conducting oxides-an up-to-date overview," Materials, vol. 5, pp. 661-683, 2012.

[47] T. L. Reitz, S. Ahmed, M. Krumpelt, R. Kumar, and H. H. Kung, "Characterization of $\mathrm{CuO} / \mathrm{ZnO}$ under oxidizing conditions for the oxidative methanol reforming reaction," Journal of Molecular Catalysis A: Chemical, vol. 162, no. 1-2, pp. 275-285, 2000.

[48] Y. Choi, K. Futagami, T. Fujitani, and J. Nakamura, "Role of ZnO in $\mathrm{Cu} / \mathrm{ZnO}$ methanol synthesis catalysts-morphology effect or active site model?" Applied Catalysis A: General, vol. 208, no. 1-2, pp. 163-167, 2001.

[49] S. H. Jeong, B. N. Park, S. B. Lee, and J.-H. Boo, "Structural and optical properties of silver-doped zinc oxide sputtered films," Surface and Coatings Technology, vol. 193, no. 1-3, pp. 340-344, 2005.

[50] T. Minami, "Present status of transparent conducting oxide thin-film development for Indium-Tin-Oxide (ITO) substitutes," Thin Solid Films, vol. 516, no. 17, pp. 5822-5828, 2008.

[51] H. Enoki, T. Nakayama, and J. Echigoya, "The electrical and optical properties of the $\mathrm{ZnO}-\mathrm{SnO}_{2}$ thin films prepared by $\mathrm{RF}$ magnetron sputtering," Physica Status Solidi A, vol. 129, pp. 181191, 1992.

[52] H. Un'no, N. Hikuma, T. Omata, N. Ueda, T. Hashimoto, and H. Kawazoe, "Preparation of $\mathrm{MgIn}_{2} \mathrm{O}_{4}-\mathrm{X}$ thin films on glass substrate by RF sputtering," Japanese Journal of Applied Physics 2: Letters, vol. 32, no. 9 A, pp. L1260-L1262, 1993.

[53] K. Yanagawa, Y. Ohki, T. Omata, H. Hosono, N. Ueda, and $\mathrm{H}$. Kawazoe, "Preparation of $\mathrm{Cd}_{1-x} \mathrm{Y}_{x} \mathrm{Sb}_{2} \mathrm{O}_{6}$ thin film on glass substrate by radio frequency sputtering," Applied Physics Letters, vol. 65, no. 4, pp. 406-408, 1994.

[54] T. Minami, H. Sonohara, S. Takata, and H. Sato, "Highly transparent and conductive zinc-stannate thin films prepared by RF magnetron sputtering," Japanese Journal of Applied Physics, vol. 33, no. 12A, pp. L1693-L1696, 1994.

[55] J. M. Phillips, J. Kwo, G. A. Thomas et al., "Transparent conducting thin films of $\mathrm{GaInO}_{3}$," Applied Physics Letters, vol. 65, no. 1, pp. 115-117, 1994.

[56] T. Minami, H. Sonohara, T. Kakumu, and S. Takata, "Highly transparent and conductive $\mathrm{Zn}_{2} \operatorname{In}_{2} \mathrm{O}_{5}$ thin films prepared by RF magnetron sputtering," Japanese Journal of Applied Physics 2: Letters, vol. 34, no. 8 A, pp. L971-L974, 1995.

[57] T. Minami, Y. Takeda, S. Takata, and T. Kakumu, "Preparation of transparent conducting $\mathrm{In}_{4} \mathrm{Sn}_{3} \mathrm{O}_{12}$ thin films by DC magnetron sputtering," Thin Solid Films, vol. 308-309, no. 1-4, pp. 13-18, 1997.

[58] M. Orita, H. Ohta, M. Hirano, and H. Hosono, "Deepultraviolet transparent conductive $\aleph_{-}-\mathrm{Ga}_{2} \mathrm{O}_{3}$ thin films," Applied Physics Letters, vol. 77, no. 25, pp. 4166-4168, 2000.

[59] H. Yanagi, K. Ueda, H. Ohta, M. Orita, M. Hirano, and H. Hosono, "Fabrication of all oxide transparent p-n homojunction using bipolar $\mathrm{CuInO}_{2}$ semiconducting oxide with delafossite structure," Solid State Communications, vol. 121, no. 1, pp. 15-17, 2001.

[60] K. Nomura, H. Ohta, K. Ueda, T. Kamiya, M. Hirano, and H. Hosono, "Thin-film transistor fabricated in single-crystalline transparent oxide semiconductor," Science, vol. 300, no. 5623, pp. 1269-1272, 2003.

[61] H. Ohta, K.-I. Kawamura, M. Orita, M. Hirano, N. Sarukura, and H. Hosono, "Current injection emission from a transparent p-n junction composed of $\mathrm{p}-\mathrm{SrCu}_{2} \mathrm{O}_{2} / \mathrm{n}$-ZnO," Applied Physics Letters, vol. 77, no. 4, pp. 475-477, 2000.

[62] H. Ohta, M. Orita, M. Hirano, and H. Hosono, "Fabrication and characterization of ultraviolet-emitting diodes composed of transparent $\mathrm{p}-\mathrm{n}$ heterojunction, $\mathrm{p}-\mathrm{SrCu}_{2} \mathrm{O}_{2}$ and $\mathrm{n}-\mathrm{ZnO}$," Journal of Applied Physics, vol. 89, no. 10, pp. 5720-5725, 2001.

[63] J. Kim, J.-H. Yun, Y. C. Park, and W. A. Anderson, “Transparent and crystalline Al-doped $\mathrm{ZnO}$ film-embedded heterojunction Si solar cell," Materials Letters, vol. 75, pp. 99-101, 2012.

[64] C. H. Kim, Y. C. Park, J. Lee et al., "Hybrid nanostructures of titanium-decorated $\mathrm{ZnO}$ nanowires," Materials Letters, vol. 65, no. 11, pp. 1548-1551, 2011.

[65] E. Shi, L. Zhang, Z. Li et al., " $\mathrm{TiO}_{2}$-coated carbon nanotubesilicon solar cells with efficiency of 15\%," Scientific Reports, vol. 2, no. 884, pp. 1-5, 2012.

[66] Y. Jin, J. Wang, B. Sun, J. C. Blakesley, and N. C. Greenham, "Solution-processed ultraviolet photodetectors based on colloidal ZnO nanoparticles," Nano Letters, vol. 8, no. 6, pp. 16491653,2008 .

[67] H. Kim, J. Kim, E. Lee, D.-W. Kim, J.-H. Yun, and J. Yi, "Effect of the short collection length in silicon microscale wire solar cells," Applied Physics Letters, vol. 102, no. 19, Article ID 193904, 2013.

[68] J. Kim, E. Lee, M. Ju et al., "Surface-concentrated light and efficient carrier collection in microhole-patterned Si solar cells," Optics Express, vol. 21, no. 13, pp. A607-A615, 2013. 
[69] H. Tan, R. Santbergen, A. H. M. Smets, and M. Zeman, "Plasmonic light trapping in thin-film silicon solar cells with improved self-assembled silver nanoparticles," Nano Letters, vol. 12, no. 8, pp. 4070-4076, 2012.

[70] T. Minami, "Substitution of transparent conducting oxide thin films for indium tin oxide transparent electrode applications," Thin Solid Films, vol. 516, no. 7, pp. 1314-1321, 2008.

[71] J. van Deelen, H. Rendering, H. H. Mannetje et al., "Highly improved transparent conductors by combination of TCOs and metallic grids," in Proceedings of the 35th IEEE Photovoltaic Specialists Conference (PVSC '10), pp. 992-994, usa, June 2010. 

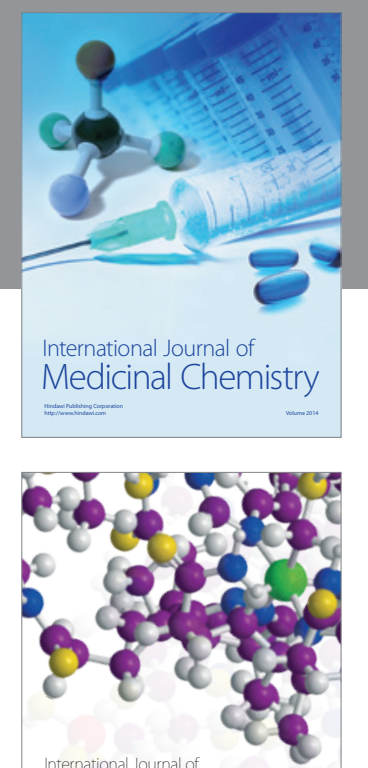

\section{Carbohydrate} Chemistry

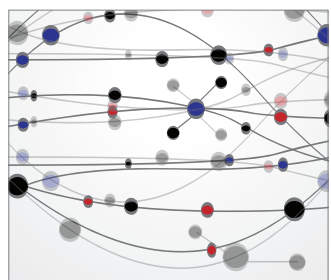

The Scientific World Journal
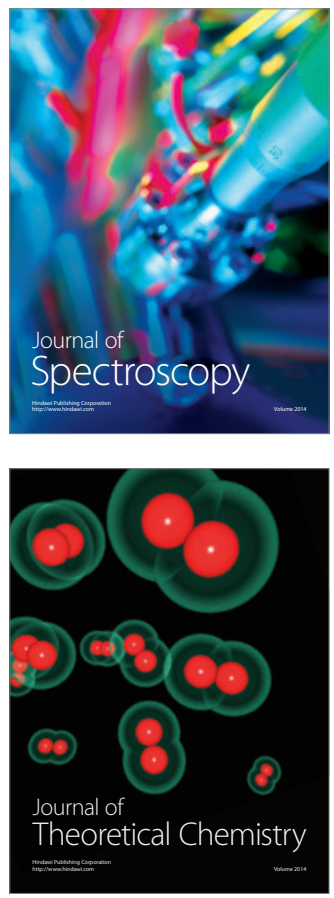
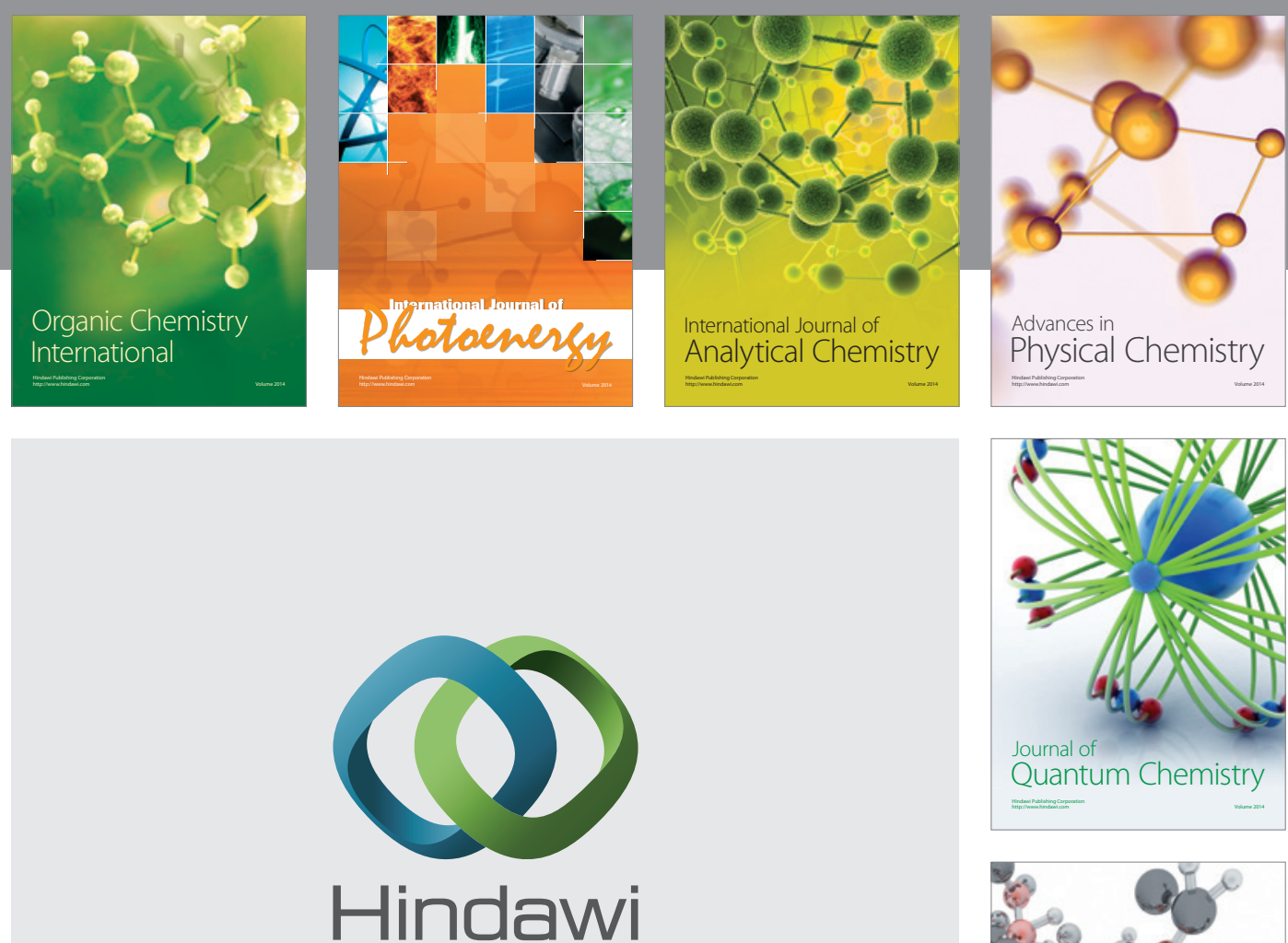

Submit your manuscripts at

http://www.hindawi.com

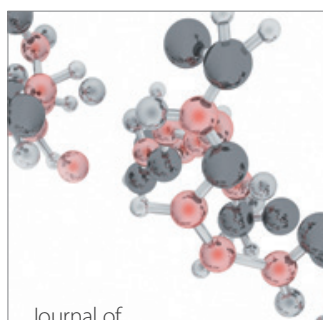

Analytical Methods

in Chemistry

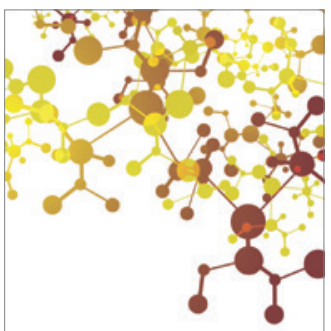

Journal of

Applied Chemistry

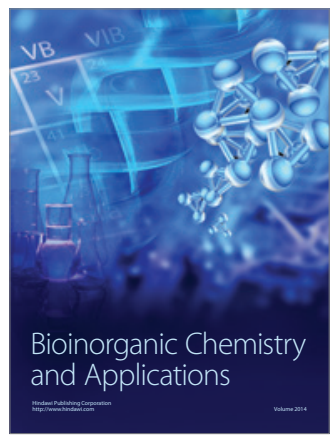

Inorganic Chemistry
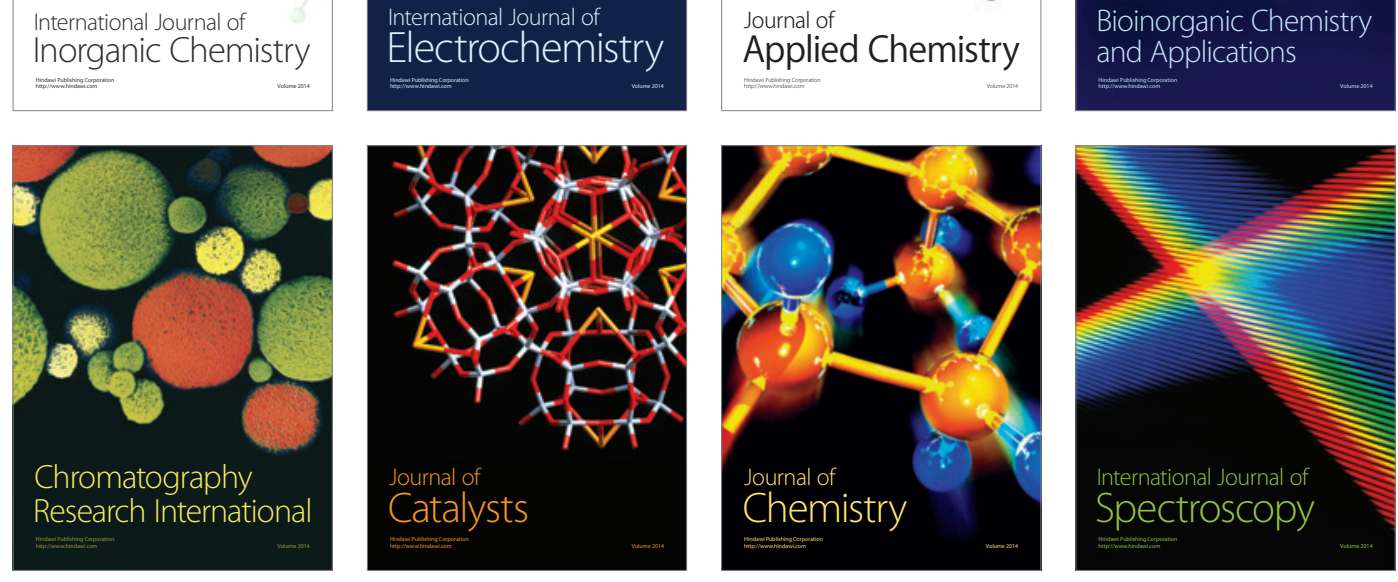